ARTICLE

DOI: $10.1038 / s 41467-018-04974-3$

\title{
Act1 is a negative regulator in $T$ and $B$ cells via direct inhibition of STAT3
}

Cun-Jin Zhang 1,2,3, Chenhui Wang 1,4,5, Meiling Jiang ${ }^{1,6}$, Chunfang Gu', Jianxin Xiao ${ }^{1}$, Xing Chen', Bradley N. Martin ${ }^{1}$, Fangqiang Tang${ }^{1}$, Erin Yamamoto ${ }^{1}$, Yibo Xian¹, Han Wang ${ }^{1}$, Fengling Li , R. Balfour Sartor ${ }^{7,8}$, Howard Smith ${ }^{9}$, M. Elaine Husni ${ }^{9}$, Fu-Dong Shi ${ }^{2,3,10}$, Ji Gao ${ }^{11}$, Julie Carman ${ }^{11}$, Ashok Dongre ${ }^{11}$, Susan C. McKarns ${ }^{12,13}$, Ken Coppieters ${ }^{14}$, Trine N. Jørgensen ${ }^{1}$, Warren J. Leonard ${ }^{15} \&$ Xiaoxia Li (i) ${ }^{1}$

Although Act1 (adaptor for IL-17 receptors) is necessary for IL-17-mediated inflammatory responses, Act1- (but not I/17ra-, I/17rc-, or I/17rb-) deficient mice develop spontaneous SLEand Sjögren's-like diseases. Here, we show that Act1 functions as a negative regulator in $\mathrm{T}$ and B cells via direct inhibition of STAT3. Mass spectrometry analysis detected an Act1-STAT3 complex, deficiency of Act1 (but not I/17ra-, I177rc-, or I117rb) results in hyper IL23- and IL-21-induced STAT3 activation in T and B cells, respectively. IL-23R deletion or blockade of IL-21 ameliorates SLE- and Sjögren's-like diseases in Act1-/- mice. Act1 deficiency results in hyperactivated follicular Th17 cells with elevated IL-21 expression, which promotes T-B cell interaction for B cell expansion and antibody production. Moreover, antiIL-21 ameliorates the SLE- and Sjögren's-like diseases in Act1-deficient mice. Thus, IL-21 blocking antibody might be an effective therapy for treating SLE- and Sjögren's-like syndrome in patients containing Act1 mutation.

\footnotetext{
${ }^{1}$ Department of Inflammation and Immunity, Lerner Research Institute, Cleveland Clinic, Cleveland, OH 44106, USA. ${ }^{2}$ Department of Neurology, Tianjin Neurological Institute, Tianjin Medical University General Hospital, Tianjin 300051, China. ${ }^{3}$ Center for Neuroinflammation, Beijing Tiantan Hospital, Capital Medical University, Beijing 100050, China. ${ }^{4}$ Key Laboratory of Molecular Biophysics of the Ministry of Education, College of Life Science and Technology, Huazhong University of Science and Technology, Wuhan 430074, China. ${ }^{5}$ Wuhan Institute of Biotechnology, Wuhan 430200, China. ${ }^{6}$ Institute of Radiation Medicine, Chinese Academy of Medical Sciences and Peking Union Medical College, Tianjin 300192, China. ${ }^{7}$ National Gnotobiotic Rodent Resource Center, Department of Medicine and Center for Gastrointestinal Biology and Disease, University of North Carolina, Chapel Hill, NC 27599, USA. ${ }^{8}$ Department of Microbiology and Immunology, University of North Carolina, Chapel Hill, NC 27599, USA. ${ }^{9}$ Department of Rheumatologic and Immunologic Disease, Cleveland Clinic, Cleveland, OH 44106, USA. ${ }^{10}$ Department of Neurology, Barrow Neurological Institute, St. Joseph's Hospital and Medical Center, Phoenix, AZ 85013, USA. ${ }^{11}$ Discovery Biology, Bristol-Myers Squibb, Princeton, NJ 08540, USA. ${ }^{12}$ Department of Surgery, University of Missouri School of Medicine, Columbia, MO 65212, USA. ${ }^{13}$ Department of Molecular Microbiology and Immunology, University of Missouri School of Medicine, Columbia, MO 65212, USA. ${ }^{14}$ Type 1 Diabetes Center, Novo Nordisk A/S, Søborg 2860, Denmark. ${ }^{15}$ Laboratory of Molecular Immunology and the Immunology Center, National Heart, Lung, and Blood Institute, National Institutes of Health, Bethesda, MD 20892, USA. These authors contributed equally: Cun-Jin Zhang, Chenhui Wang, Meiling Jiang. Correspondence and requests for materials should be addressed to X.L. (email: lix@ccf.org)
} 
S ystemic lupus erythematosus (SLE) is a complex, chronic systemic autoimmune disorder with a heterogeneous presentation commonly targeting joints, skin, hematologic, and kidneys without a known cure ${ }^{1,2}$. Th17 cells are a population of proinflammatory $\mathrm{CD}^{+}$effector $\mathrm{T}$ cells that produce interleukin 17A (IL-17A), IL-17F, IL-21, and IL-22. While Th17 cells play important roles in immune homeostasis and host defense, an overactive Th17 response has been implicated in various inflammatory and autoimmune conditions including psoriasis, SLE, and Sjögrens syndrome ${ }^{3-9}$.

The signaling cascade of IL-17, the signature cytokine of Th17 cells, requires a key signaling molecule, Actl (also known as TRAF3IP2 or CIKS) to propagate downstream signaling events in tissue cells, including activation of the transcription factor NF$\kappa B^{10-13}$. The absence of Act1 leads to resistance to IL-17mediated inflammation in mouse models of experimental autoimmune encephalomyelitis (EAE) and asthma ${ }^{10,14-16}$. Although Act1 is necessary for IL-17-mediated inflammatory responses, Act $1^{-/-}$mice develop hyper Th17 responses (with increased IL17 producing $\mathrm{CD}^{+} \mathrm{T}$ cells in lymph nodes and spleen) and spontaneous inflammatory/autoimmune diseases, including skin inflammation, SLE-like nephritis, and Sjögren's-like disease ${ }^{3-6}$. Notably, multiple genome-wide association studies have linked a variant of Actl with substitution of asparagine for aspartic acid at position 10 (SNP-D10N) to susceptibility to psoriasis and SLE ${ }^{17-}$ 20 . We reported that $\mathrm{ACT} 1^{\mathrm{D} 10 \mathrm{~N} / \mathrm{D} 10 \mathrm{~N}} \mathrm{~T}$ cells exhibit a dysregulated and hyperactive Th17 response, implicating an intricate mechanism by which this single nucleotide polymorphism can be linked to human disease $e^{3,21}$. Supporting cell-specific effects, we demonstrated that the hyperactive Th17 response in Act1-/mice was $\mathrm{T}$ cell intrinsic. One critical question is whether the hyper Th17 response in $A c t 1^{-/-}$mice is required for the SLE-like nephritis and Sjögren's-like disease associated with Actl deficiency. Furthermore, the molecular mechanism of how Actl deficiency results in hyper Th17 response remains unclear. Notably, although a hyper Th17 response (elevated IL-17) was also observed in $1117 \mathrm{ra}^{-/-}$and $117 \mathrm{rc}^{-/-}$mice, SLE- and Sjögren's-like diseases were not observed in these mice, indicating that the autoimmune phenotype in $A c t 1^{-/-}$mice is probably not simply due to lack of IL-17 signaling. In support of this, whereas the hyperactive Th17 response in $A c t 1^{-1-}$ mice was $\mathrm{T}$ cell intrinsic ${ }^{3}$, the hyperactive Th17 response associated with $I L-17 R A$ deficiency was not observed in T cell-specific IL-17RA-deficient mice $^{22}$.

In this study, we report that Actl plays a critical role in modulating Th17 polarization via direct inhibition of STAT3. a

Stat3 peptide sequences
detected by mass spectrometry

\begin{tabular}{|l|}
\hline 1. VVENLQDDFDFNYK \\
2. IITAATAAQQGGQANHPTAAVVTEK \\
3. SIVSELAGLLSAMEYVQK \\
4. VCIDKDSGDVAALR \\
5. FLQESNVLYQHNLR \\
6. TLTDEELADWK \\
7. YLEQLHQLYSDSFPMELR \\
8. FPELNYQLK \\
9. TGVQFTTK \\
10. KFNILGTNTK \\
11. VQDLEQK \\
12. ESHATLVFHNLLGEIDQQYSR \\
13. KLEELQQK \\
14. RVQDLEQK \\
15. YLEKPMEIAR
\end{tabular}

b

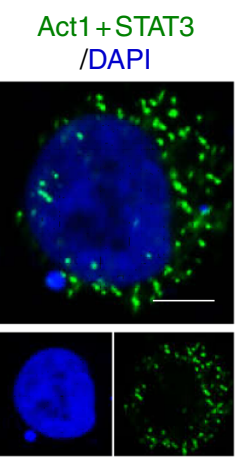

d e

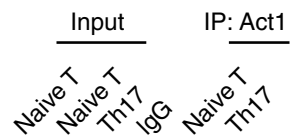

IL6+IL23+ +++++

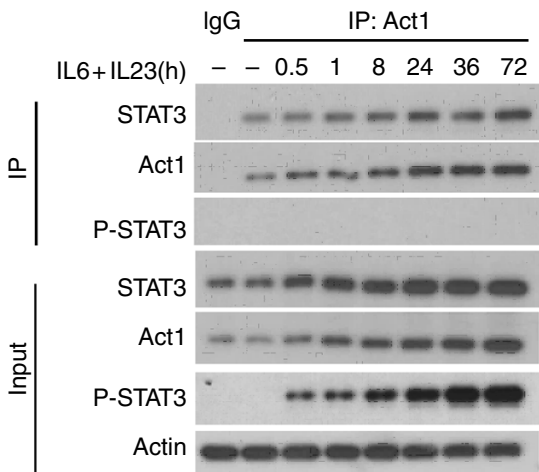

C WT
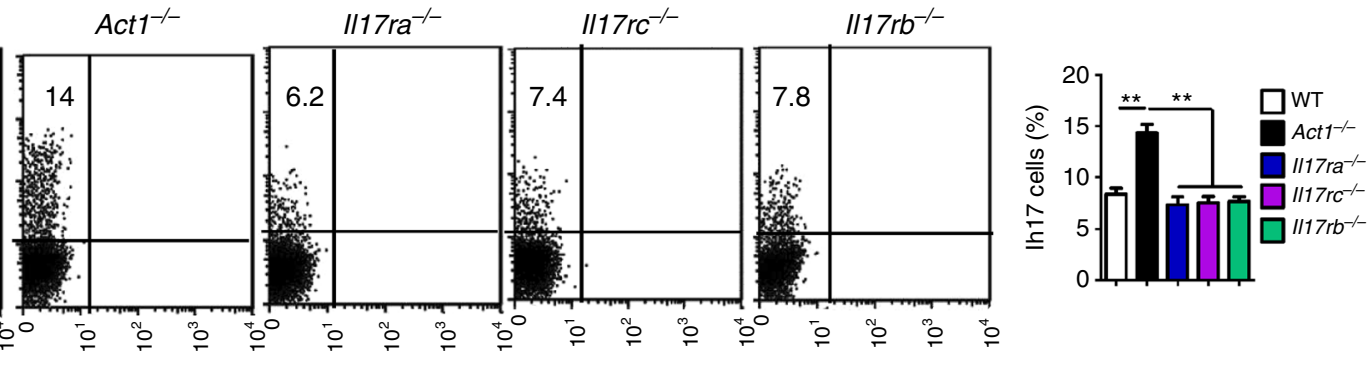

Fig. 1 Act1 physically interacts with STAT3. a Mass spectrometry analysis of Act1-associated proteins after immunoprecipitation via anti-Flag beads from lysates of HeLa cells transiently transfected to express Act1-Flag. Fifteen matched peptide sequences that correspond to STAT3 were identified. $\mathbf{b}$ HeLa cells were co-transfected with V5-Act1 and Flag-STAT3, followed by Duolink assay, in which mouse anti-V5 and rabbit anti-Flag antibody were used. Green dots present the interaction of STAT3 and Act1. Scale bars: $10 \mu \mathrm{m}$. c Naive T cells isolated from spleens of indicated mice were polarized to Th17 with IL-23 + IL-6 for 3 days, followed by intracellular staining for IL-17A and IFN $\gamma$. d WT Naive T cells isolated from spleen were polarized into Th17 cells with IL-23 + IL-6. Lysates were then immunoprecipitated with anti-Act1 followed by western analysis of indicated proteins. e Naive CD4 ${ }^{+}$T cells were stimulated with IL-6 +23 for the indicated time. Cells were then lysed and immunoprecipitated with anti-Act1 followed by western analysis with the indicated antibodies. Graphed as mean \pm SEM. ${ }^{\star \star} p<0.01$. N =4-6/group. Two-tailed Student's $T$ test. All the data presented were from three independent experiments 


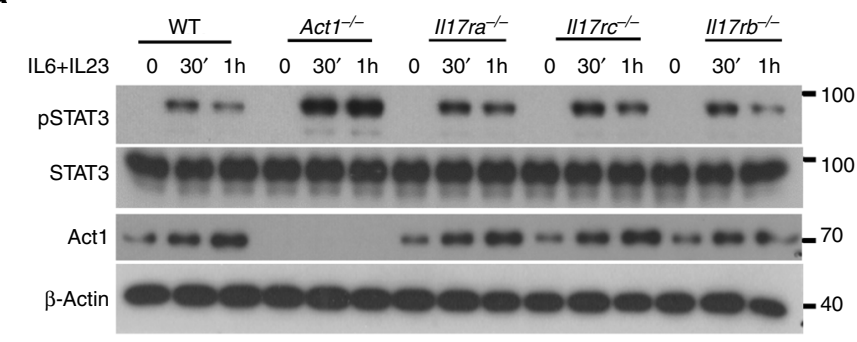

b

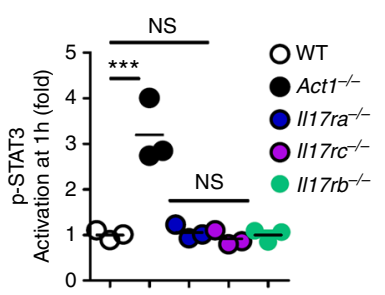

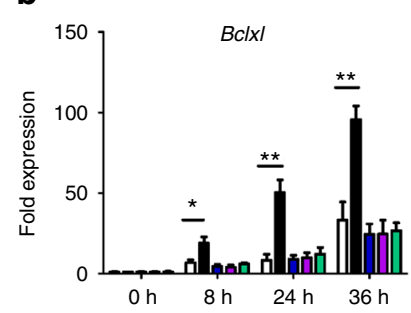
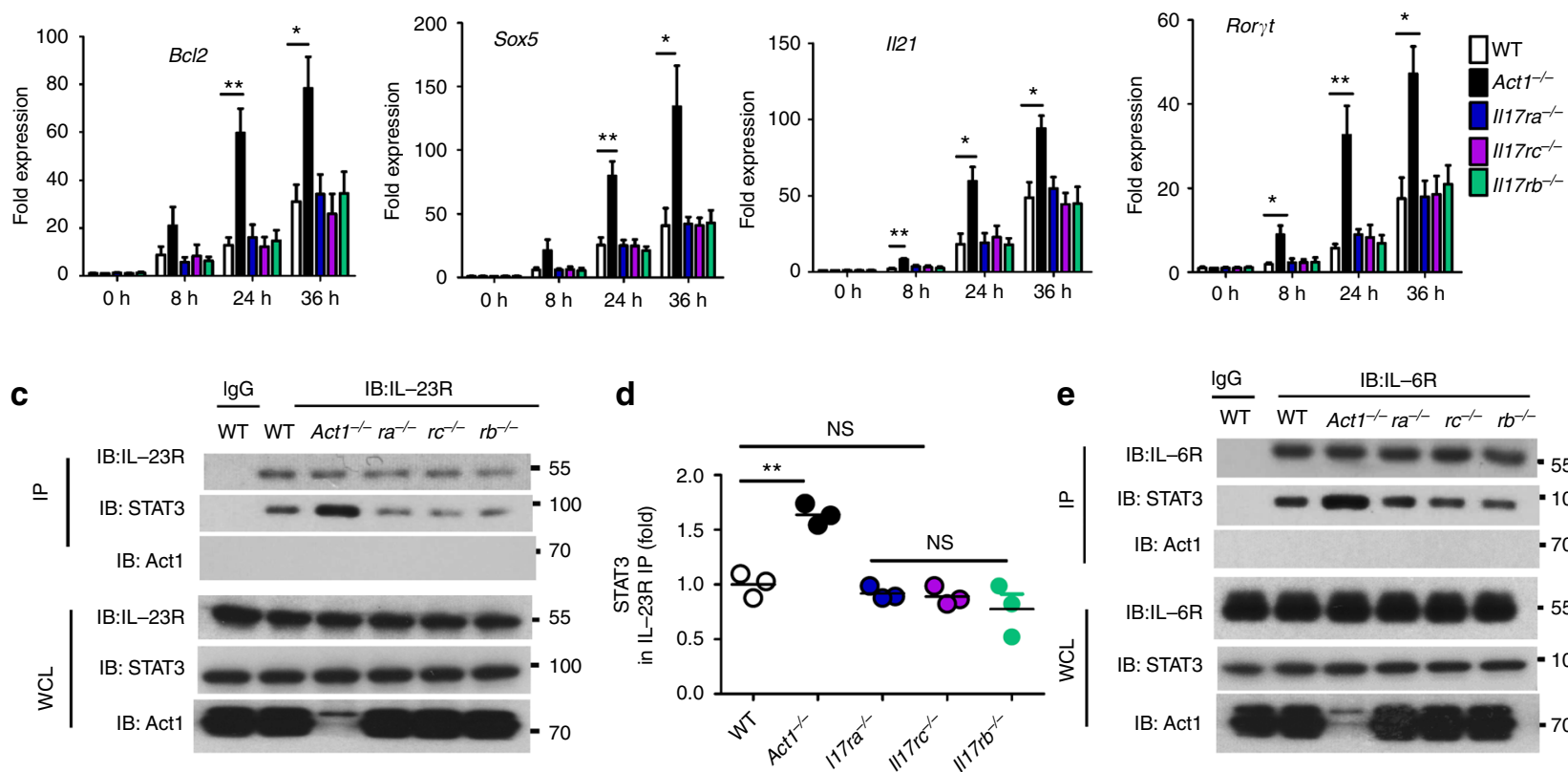

e $\quad \frac{\lg G}{\mathrm{WT}} \frac{\mathrm{IB}: \mathrm{IL}-6 \mathrm{R}}{\mathrm{WT} \quad A c t 1^{-/} \mathrm{ra}^{-/} r \mathrm{rc}^{-/} r \mathrm{rb}^{-/}}$
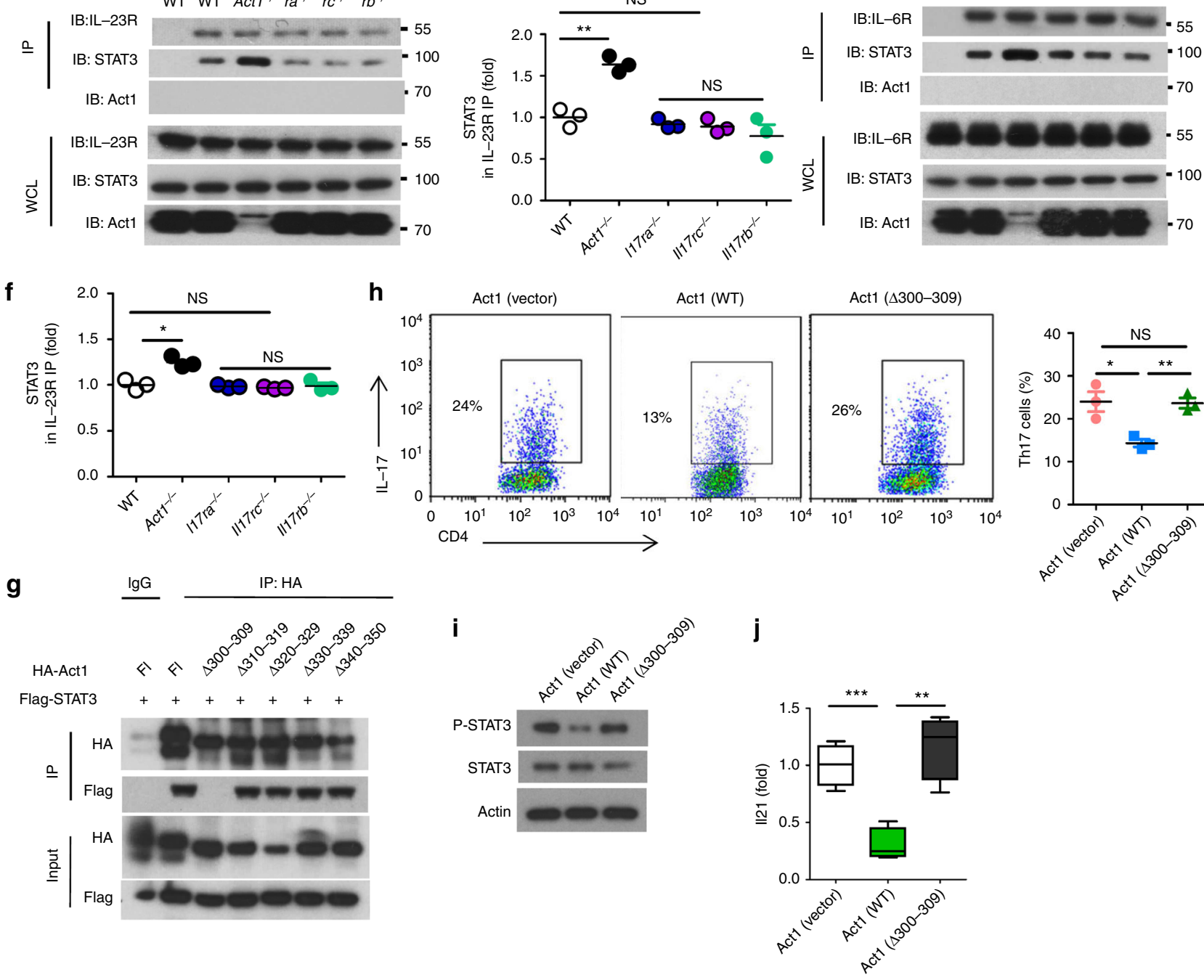

j

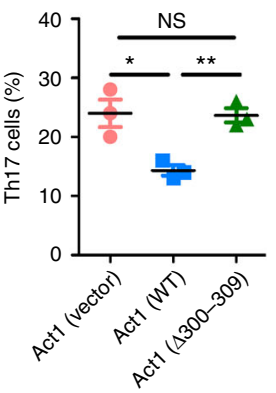


Fig. 2 Act1 competes with IL-23R for STAT3 binding and negatively regulates STAT3 activation. a Naive T cells stimulated with IL-23 + IL-6 for the indicated times, followed by western analysis of indicated proteins. STAT3 phosphorylation was quantified as a ratio of phosphorylated-to-total STAT3. Data presented as fold of induction of the cells from knockouts over the wild-type cells. b RT-PCR analysis of STAT3-target genes in Naive T cells stimulated with IL-23 + IL-6 for the indicated times. c-f Naive T cells were stimulated with IL-23 and IL-6 for $1 \mathrm{~h}$, followed by immunoprecipitation with anti-IL23R (c, d) or anti-IL6R $(\mathbf{e}, \mathbf{f})$ and western analysis of indicated proteins. STAT3 levels of the immunoprecipitates were quantified as percentage of total STAT3 in the cell lysates. $\mathbf{g}$ HeLa cells were transiently co-transfected full-length STAT3 with control vector, Flag-tagged full-length Act1 (fl), or Act1 deletion mutants. Lysates were immunoprecipitated with anti-HA (HA-Act1), followed by western analysis with the indicated antibodies. h-j WT-Act1 and Act1 $\triangle$ 300-309 mutant in retroviral vector (carrying RPF) were introduced into the primary Act $1^{-/}$- naive T cells. Sorted RFP ${ }^{+}$naive T cells were polarized to Th17 cells in the presence of IL- $6+$ IL-23 and quantified as percentage of CD4+ T cells (h), western analysis of indicated proteins (i), and RT-PCR analysis of IL-21 gene expression (j). Graphed as mean \pm SEM. ${ }^{\star} p<0.05,{ }^{\star \star} p<0.01,{ }^{\star \star \star} p<0.001 . N=4-6 /$ group. Two-tailed Student's $T$ test. All the data presented were from three independent experiments

Mass spectrometry analyses followed by co-immunoprecipitation showed that Actl (but not the SNP-D10N mutant) was able to directly interact with and suppress STAT3 activation in Th17 cells. Deficiency of Act1 (but not Il17ra-, Il17rc-, or Il17rb) results in hyper IL-23-induced STAT3 activation in naive $\mathrm{CD} 4^{+} \mathrm{T}$ cells and increases IL-21 expression. IL-23R deletion reduces Th17 cells and ameliorates autoimmune diseases in $A c t 1^{-1-}$ mice, implicating the importance of hyper Th17 cells (with increased STAT3 activation and IL-21 expression) for the autoimmune diseases associated with Act1 deficiency. Furthermore, deficiency of Act1 (but not Il17ra-, Il17rc-, or Il17rb) results in hyper IL-21induced STAT3 activation in B cells. Deletion of IL-21R or blockade of IL-21 with an anti-IL-21 neutralizing antibody ameliorates the development of Sjögren's and SLE-like diseases in Act $1^{-/}$mice. These findings indicate that Act1 modulates IL-23/ IL-21-dependent autoimmunity via suppression of STAT3 activation, providing a mechanism for the association of the SNPD10N mutation with SLE.

\section{Results}

Act1 suppresses IL-23-induced STAT3 activation in Th17 cells. We previously reported that the hyperactive Th17 response in Act $1^{-1-}$ mice was $\mathrm{T}$ cell intrinsic ${ }^{3}$, whereas the hyperactive Th17 response associated with $I l 17 \mathrm{ra}$ deficiency was not observed in $\mathrm{T}$ cell-specific Il17ra-deficient mice ${ }^{22}$. Thus, we hypothesize that Act1 may play a direct role in modulating Th17 polarization, which is independent of IL-17 signaling. Mass spec analysis of Act1-coimmunoprecipitates showed that STAT3 is a potential Act1-interacting protein (Fig. 1a and Supplementary Fig. 1a). We validated the interaction between Act1 and STAT3 by immunoprecipitation-western analysis and proximity ligation assay (Fig. 1b, d, e). IL-23 and IL-6 are the key cytokines for inducing human and murine Th17 cell differentiation/expansion by activating STAT3 ${ }^{23,24}$. When naive $\mathrm{T}$ cells were polarized into Th17 cells by IL-23 and IL-6, deficiency of Act 1 in T cells resulted in increased $\mathrm{IL}-17^{+} \mathrm{CD} 4^{+} \mathrm{T}$ cells (Fig. 1c), whereas Actl deficiency had no impact on Th1 or Th2 cell polarization (Supplementary Fig. 1b, c). Consistently, the hyper Th17 phenotype was also observed in Act1 knockdown cells (Supplementary Fig. 1d, e). On the other hand, deficiency of Il17ra, Il17rc, or Ill7rb had no impact on the polarization of naive $\mathrm{CD}^{+} \mathrm{T}$ cells into Th17 cells ex vivo (Fig. 1c). While Actl expression was induced during Th17 cell polarization by IL-23/IL-6, the endogenous Act1 formed a complex with STAT3, but not with other STATs, in Th17 cells, implicating a potential role for STAT3 in Act1mediated modulation of Th17 cells (Fig. 1d). Notably, phosphorylated STAT3 was not detected in Act1-immunoprecipitates, suggesting that Act1 probably formed a complex with unphosphorylated STAT3 (Fig. 1d, e).

We then examined IL-23 and IL- 6 signaling in wild-type and Act1-deficient naive $\mathrm{CD} 4{ }^{+} \mathrm{T}$ cells. Act1 deficiency enhanced IL23/IL-6-induced STAT3 phosphorylation (but not p-STAT4 or pSTAT5) in naive $\mathrm{CD}^{+} \mathrm{T}$ cells (Fig. 2a and Supplementary
Fig. 1f, g). Consistent with the fact that Act1 deficiency had no impact on IL-4-polarized Th2 cells, IL-4-induced phosphorylation of STAT5 and STAT6 were not affected by Act1 deficiency (Supplementary Fig. 1h). In agreement with the hyper STAT3 activation, Act1 deficiency indeed enhanced IL-23/IL-6-induced expression of STAT3-target genes, including $B c l x l, B c l 2$, Sox5, Il21, and Roryt (Fig. 2b and Supplementary Fig. 1i). On the other hand, Il17ra, Il17rc, or Il17rb deficiency had no impact on IL-23/ IL-6-induced STAT3 phosphorylation or the expression of STAT3-target genes in naive $\mathrm{CD}^{+} \mathrm{T}$ cells (Fig. 2a, b). Importantly, the IL-6R and IL-23R levels were comparable between wild-type and Act1-deficient Th17 cells. Instead, the interaction of STAT3 to IL-23R, and to a lesser degree to IL-6R, was increased in Act1-deficient (but not Il17ra, Il17rc, or Il17rbdeficient) naive $\mathrm{CD}^{+}{ }^{+} \mathrm{T}$ cells compared to the wild-type cells in response to IL-23 or IL-6 stimulation (Fig. 2c-f and Supplementary Fig. 1j). These results suggest that the Act1-STAT3 interaction may suppress IL-23/IL-6-induced STAT3 activation by attenuating STAT3's recruitment to their receptors. We found that amino acid residues 300-309 of Act1 are required for its interaction with STAT3, but not for the interaction of Act1 with other signaling molecules such as TRAFs (Fig. $2 \mathrm{~g}$ and Supplementary Fig. 2a). Furthermore, wild-type Act1, but not Act1 mutant $(\Delta 300-309)$, inhibited the interaction of STAT3 with IL-23R and IL-6R (Supplementary Fig. 2b-e). We have introduced WT-Act1 and Act1 $\Delta 300-309$ mutant in retroviral vector into the primary $A c t 1^{-1-}$ naive $\mathrm{T}$ cells, followed by polarization to Th17 in the presence of IL-6+IL-23. The results showed that the re-introduction of WT-Act1 but not Act1 $\triangle 300-309$ mutant corrected the hyper $\mathrm{T}$ phenotype of Act1-deficient cells (Fig. $2 \mathrm{~h}-\mathrm{j}$ ). Taken together, our results suggest that Act1 suppresses IL-23/IL-6-induced STAT3 activation thereby modulating Th17 polarization. Since deficiency of Il17ra, Il17rc, or Il17rb had no impact on STAT3 activation or the polarization of naive CD4 ${ }^{+} \mathrm{T}$ cells into Th17 cells ex vivo, our results indicate that the modulation of Th17 cells by the Act1-STAT3 axis is independent of IL-17 signaling.

IL-23R is required for the autoimmunity in $A_{c t 1}{ }^{-/-}$mice. Although Act1 is necessary for IL-17-mediated inflammatory responses, Act1-deficient mice develop spontaneous inflammatory/autoimmune diseases, including hypergammaglobulinemia, elevated serum autoantibodies, SLE-like nephritis, and Sjögren'slike disease ${ }^{3-6}$. Since Act1-deficient T cells showed hyper IL-23R signaling, we generated $A c t 1^{-/}$mice also deficient in the receptor for IL-23 (Act1 ${ }^{-/} I l 23 r^{-1-}$ mice). The Act $1^{-/-} I l 23 r^{-/-}$ showed reduced Th17 cells in the spleen of $A c t 1^{-1-} I l 23 r^{-1-}$ mice as compared with $A c t 1^{-1-}$ mice (Supplementary Fig. 3a-d). Notably, Actl expression was not altered in native CD4 T cells and B cells from wild-type and $I l 23 r^{-1-}$ mice (Supplementary Fig. 3a). Furthermore, Act $1^{-1-} I l 23 r^{-1-}$ mice showed reduced anti-histone, anti-dsDNA and anti-ssDNA IgG production compared to that of littermate control $A c t 1^{-/-}$mice, albeit not to 
a
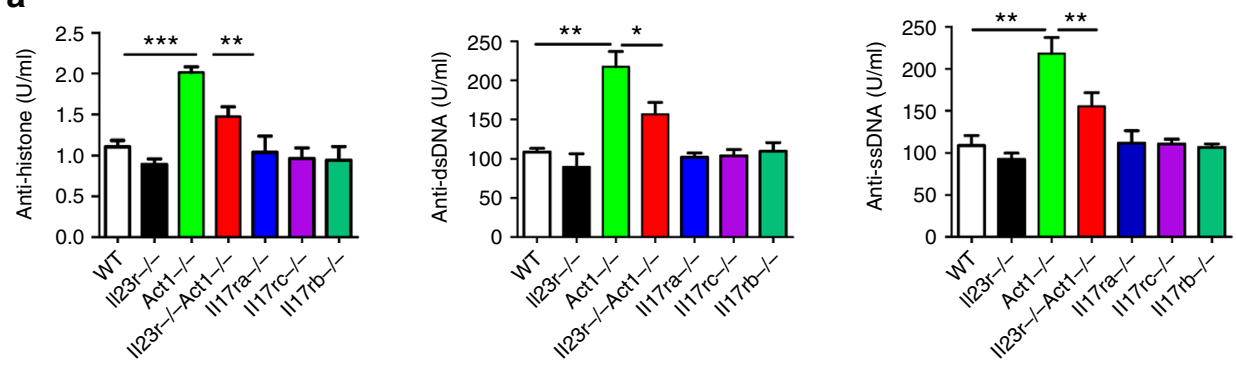

b

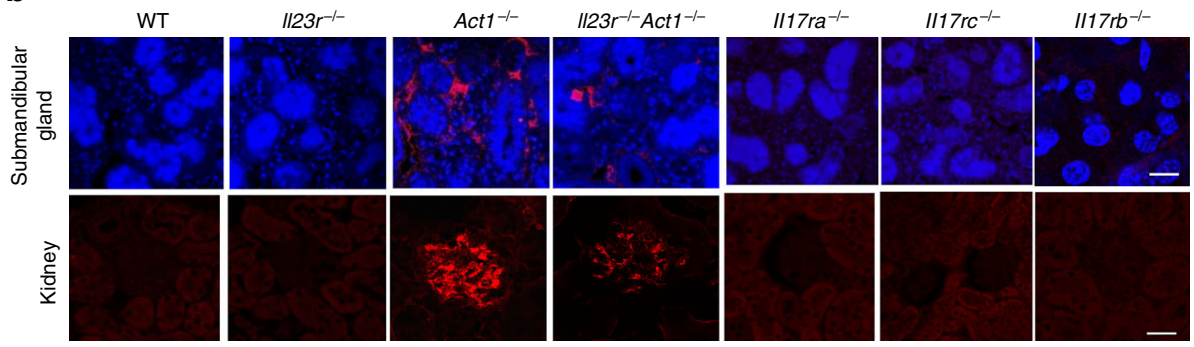

C
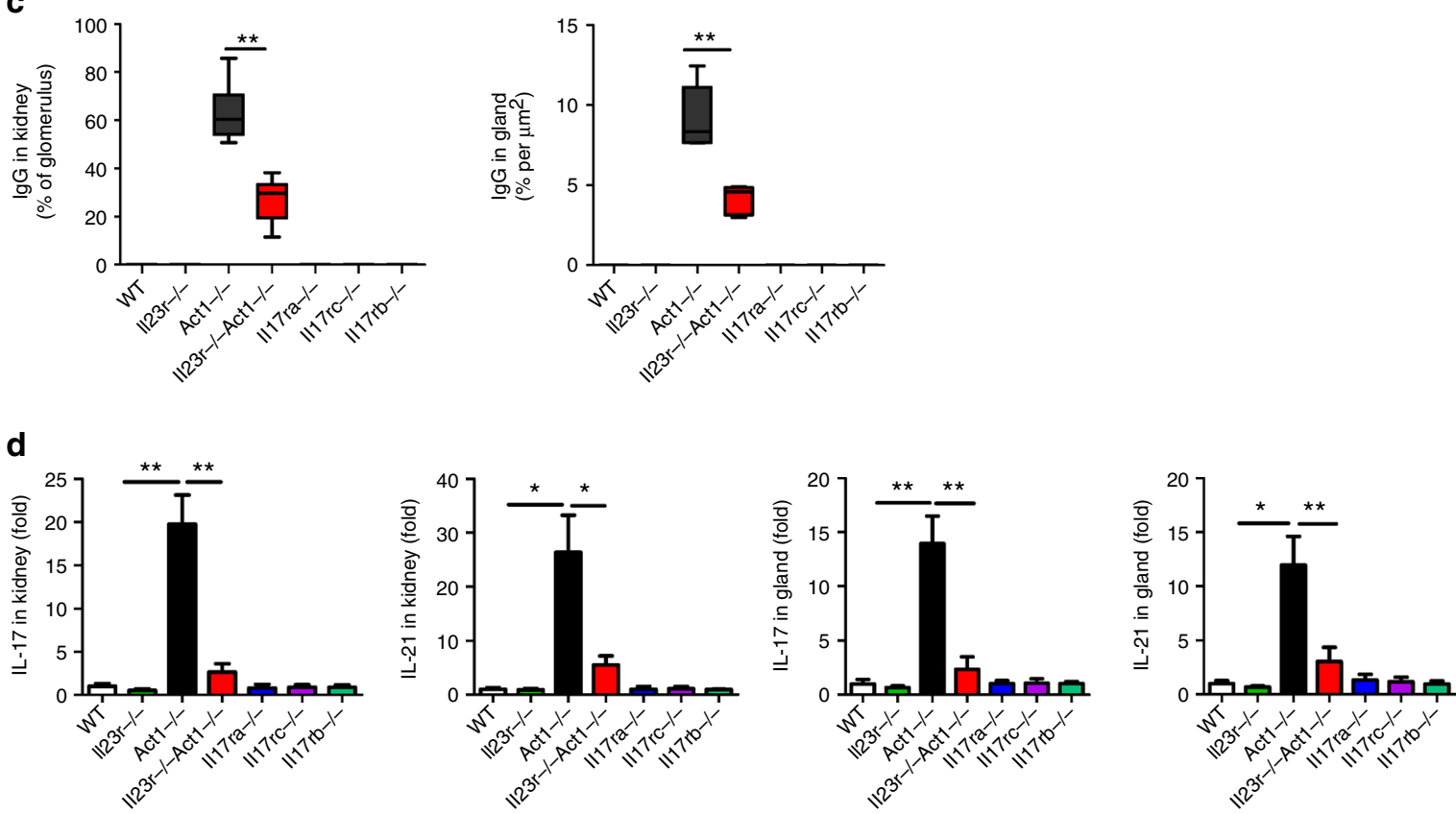

Fig. $3 \mathrm{IL}-23 \mathrm{R}$ is required for the autoimmune diseases in Act1-/- mice. a Serum samples were obtained from 8-month-old mice with indicated phenotypes and analyzed for levels of anti-histone, anti-dsDNA, and anti-ssDNA IgG. b Kidneys and submandibular glands were harvested and quick frozen in OCT, followed by immunofluorescence staining for IgG (red). Scale bars, $50 \mu \mathrm{m}$. c Quantification of lgG deposit in glomerulus of kidney and submandibular gland. d RT-PCR analysis of IL-17 and IL-21 transcripts in submandibular gland and kidney from 8-month-old mice with indicated genotypes. N=4-6/group. Mean \pm SEM. ${ }^{\star} p<0.05 ;{ }^{\star \star} p<0.01 ;{ }^{\star \star \star} p<0.001$; Two-tailed Student's $T$ test. All the data presented were from two independent experiments

the WT level (Fig. 3a). Kidneys and submandibular glands were harvested from 8-month-old wild-type, $A c t 1^{-1-}, I l 23 r^{-1-}$, and Act $1^{-1-} I l 23 r^{-1-}$ mice, and analyzed for IgG-immune complex deposits by immunofluorescence staining. Reduced IgG deposits and inflammation were observed in $A c t 1^{-/} I l 23 r^{-1-}$ as compared with $A c t 1^{-/-}$mice (Fig. 3b,c and Supplementary Fig. 3e). Th17 signature mRNAs, including IL-17 and IL-21, were also significantly downregulated in the kidneys and glands of Act $1^{-/} I l 23 r^{-1-}$ mice (Fig. 3d). Consistent with reduced inflammation, flow cytometry showed that $A c t 1^{-/} I l 23 r^{-/-}$ kidneys and submandibular glands had much diminished levels of $\mathrm{CD}^{+} \mathrm{T}$ cells and $\mathrm{B} 220^{+} \mathrm{B}$ cells compared to that of littermate control Act $1^{-/-}$mice (Supplementary Fig. 3f-h). Taken together, these results indicate that $\mathrm{IL}-23 \mathrm{R}$ is required for the SLE- and Sjögren's-like diseases associated with Act1 deficiency. Importantly, Sjögren's-like and SLE-like diseases were not observed in the $I l 17 \mathrm{ra}^{-/-}, I l 17 \mathrm{rC}^{-/-}$, and $I l 17 \mathrm{rb} \mathrm{b}^{-/-}$mice (Fig. 3a-d). These results indicate that the autoimmune phenotype in $A c t 1^{-1-}$ mice is probably independent of the role of Act1 in IL-17 signaling.

IL-21R is required for the autoimmunity in Act $^{-/-}$mice. We further investigated the molecular and cellular mechanism for how IL-23R-dependent Th17 response promotes autoimmunity 
a

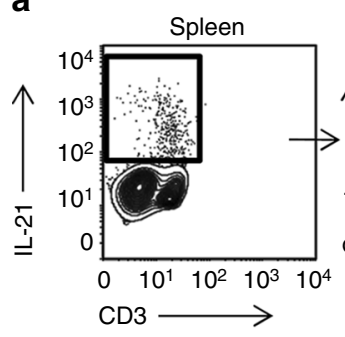

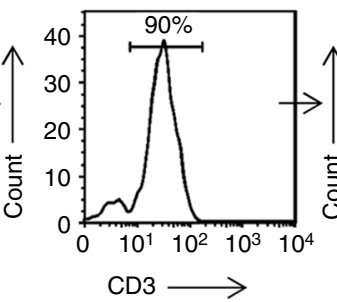

$\mathrm{CD} 3 \longrightarrow$

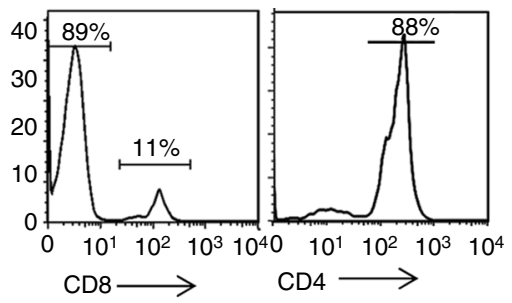

b

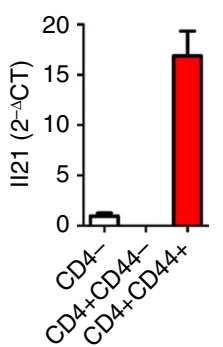

C

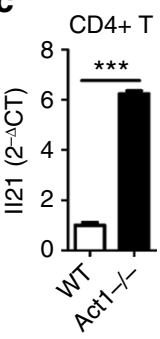

d
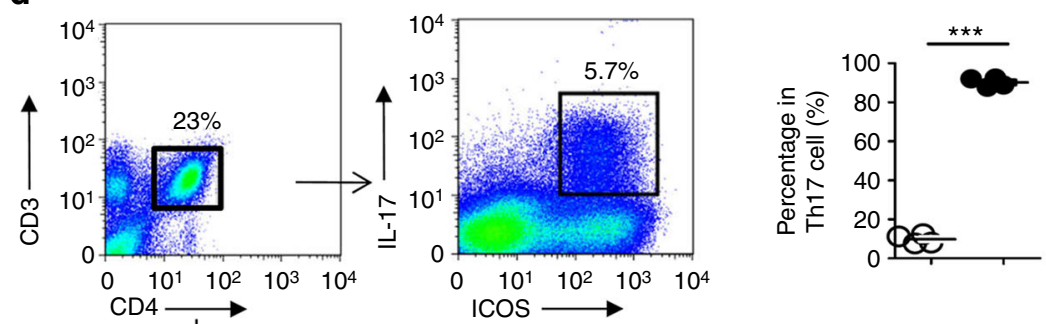

O IL-17ICOS-

- IL-17ICOS ${ }^{+}$
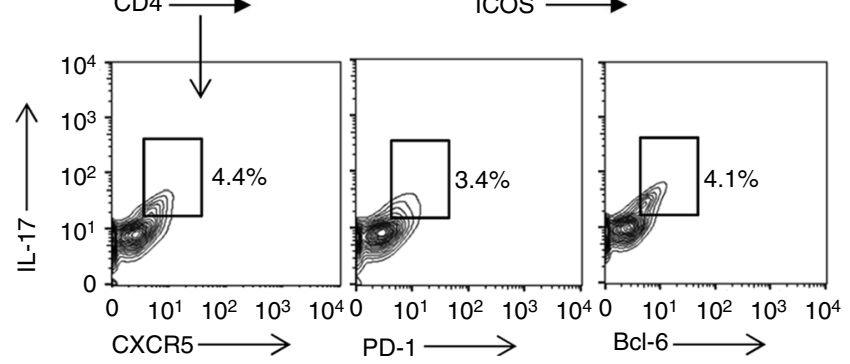

e
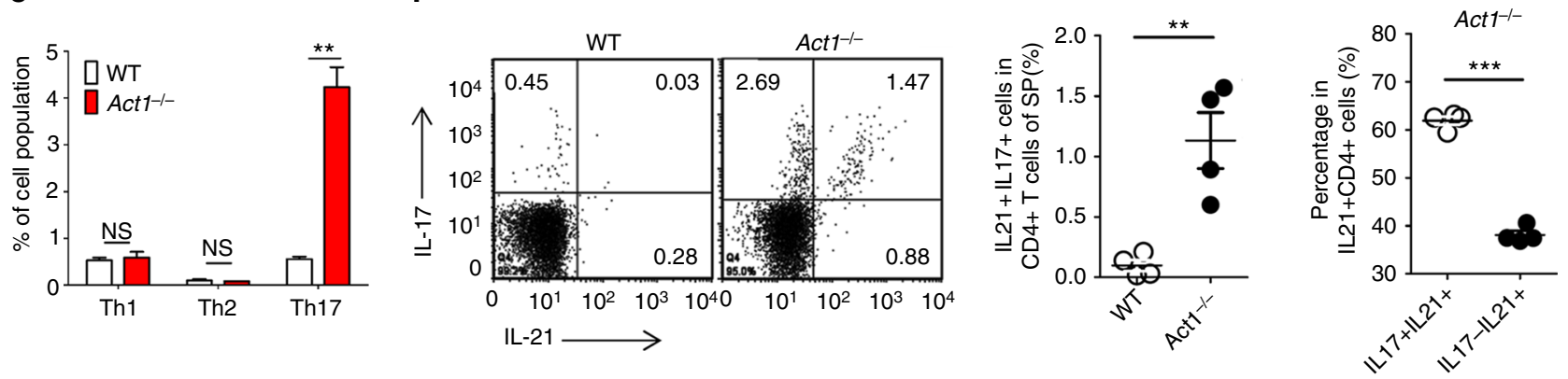

g

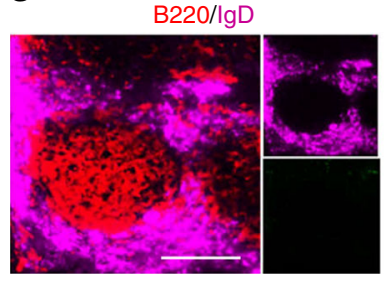

Without IL-17 staining

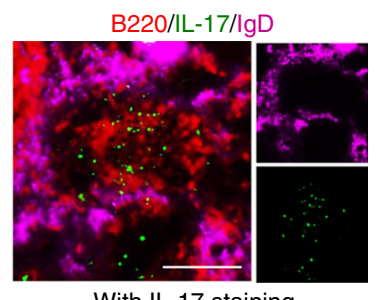

With IL-17 staining

Fig. 4 Th17 cells are the major sources of IL-21 in Act1 ${ }^{-/-}$mice. a Flow cytometry analysis of IL-21+CD3+, IL- $21^{+} \mathrm{CD} 4^{+}$, and IL-21+CD8 ${ }^{+} \mathrm{T}$ cells in spleen from 8 months old Act1-/- mice. b,c RT-PCR analysis of IL-21 transcript in the sorted CD4- ${ }^{-}$CD4 ${ }^{+} \mathrm{CD} 44^{-}$and $\mathrm{CD} 4^{+} \mathrm{CD} 44^{+} \mathrm{T}$ cells from spleen of 8 months old $A c t 7^{-/-}$mice (b) and CD4 ${ }^{+}$T cells from spleen of WT or Act ${ }^{-/-}$mice (c). d Flow cytometry analysis of ICOS + IL17 + Th17 cells and other Tfh markers (CXCR5, PD-1, and Bcl-6) in spleen of 8 months old Act ${ }^{-/-}$mice. e Flow cytometry analysis of Th1 (CD3 $\left.{ }^{+} \mathrm{CD}_{4}^{+}{ }^{+} \mathrm{FN} \gamma+{ }^{+}\right), \mathrm{Th}_{2}\left(\mathrm{CD} 3^{+} \mathrm{CD} 4+\mathrm{IL}-4^{+}\right)$, and Th17 $\left(\mathrm{CD} 3^{+} \mathrm{CD} 4^{+} \mathrm{IL} 17 A^{+}\right)$cells in spleen of 8 months old $A c t 1^{-/-}$mice and WT control mice. $\mathbf{f}$ Flow cytometry analysis of $\mathrm{CD}^{+} \mathrm{CD} 4{ }^{+} \mathrm{IL}-17^{+} \mathrm{IL}-21^{+}$ cell in spleen of 8 months old mice. $\mathbf{g}$ Spleens collected from Act1 ${ }^{-/-}$mice were stained with antibodies against B220, IL-17, and lgD. Scale bars: $100 \mu$ m. $N=4-7$ /group. Mean \pm SEM. ${ }^{\star \star} p<0.01,{ }^{\star \star \star} p<0.001$. Two-tailed Student's $T$ test. All the data presented were from two independent experiments

in Act1-deficient mice. Notably, along with IL-17 and IL-22, IL-21 production was highly enhanced in Th17 cells from the spleen of Act $1^{-1-}$ mice (Supplementary Fig. 3d). We found that CD4 ${ }^{+}$ $\mathrm{T}$ cells, but not $\mathrm{CD} 4^{-}$cells, were the main source of IL-21 production in $A c t 1^{-/}$mice (Fig. $4 \mathrm{a}-\mathrm{c}$ ). While Tfh cells are considered as a major source of IL-21 $25-27$, Th17 cells can acquire features of Tfh cells ${ }^{28-31}$. We indeed found majority of Th17 cells express ICOS, a key marker of Tfh cells ${ }^{32-36}$ (Fig. $4 \mathrm{~d}$ and Supplementary Fig. 3i). Additional Tfh cell markers (including CXCR5, PD-1, and Bcl6) were also highly expressed in CD4 ${ }^{+} \mathrm{IL}_{-}^{-}$ 
$17^{+}$cells from Act $1^{-1-}$ mice (Fig. $3 \mathrm{~d}$ and Supplementary Fig. 3i). Consistently, flow analysis indicated that Th17 with the features of Tfh cells (also called Tfh17) are the major source of IL-21 production in $A c t 1^{-/-}$spleen (Fig. 4e, $\mathrm{f}$ and Supplementary Fig. 4a). Moreover, IL- $17^{+}$cells were detected inside the B cell follicles in Act1-deficient spleen, demonstrating the presence of IL-17 ${ }^{+}$Tfh cells (referred as Tfh17 cells) (Fig. $4 \mathrm{~g}$ ).

To test the impact of IL-21 on the autoimmune phenotype in Act1-deficient mice, we generated $A c t 1^{-1-} I l 21 r^{-1-}$ mice. Act $1^{-/-} I l 21 r^{-/-}$mice showed substantially reduced production of autoantibodies, including anti-histone, anti-dsDNA, and antissDNA IgG compared to that of $A c t 1^{-/-}$mice (Fig. 5a). Kidneys and submandibular glands were harvested from 8-month-old wildtype, Act $1^{-1-}$, Il21r ${ }^{-1-}$, and $A c t 1^{-1-} I l 21 r^{-1-}$ mice, followed by immunofluorescence staining for IgG and H\&E staining. Reduced IgG deposits and inflammation were observed in $A c t 1^{-1-} I l 21 r^{-1-}$ than in $A c t 1^{-/-}$mice (Fig. 5b, c and Supplementary Fig. 4b). Flow analyses showed that $A c t 1^{-1-} I l 21 r^{-1-}$ kidneys and submandibular glands had much diminished levels of infiltrating $\mathrm{CD} 4{ }^{+} \mathrm{T}$ cells and $\mathrm{B} 220^{+} \mathrm{B}$ cells compared to that of littermate control Act1 ${ }^{-/}-$mice (Fig. 5d, e). Collectively, IL-21R deficiency abolished the autoimmune SLE-like nephritis and Sjögren's syndrome diseases associated with Actl deficiency. Although Th17 cells showed hyper STAT3 activation in response to IL-21 stimulation (Supplementary Fig. 4d), Act1 $1^{-1}-I l 21 r^{-1-}$ showed similar levels of Th17 cells and IL-21 production in the spleen compared to that in $A c t 1^{-1-}$ mice (Fig. 5f, g). Taken together, these data suggest that the impact of IL21R deficiency on Actl-deficient mice is likely not through the ablation of Th17 cells.

Th17-derived IL-21 promotes T-B cell interaction in Act1 $^{-1-}$ mice. A prior study showed that Th17 cells can serve as effective helper cells, functioning as B-cell helpers in the induction of a proliferative response of $\mathrm{B}$ cells in vitro and antibody production with class switch recombination in vivo ${ }^{28}$. Since IL-21 is known to help B cells, we hypothesize that the elevated IL-21 from hyper Th17 cells of $A c t 1^{-/-}$mice leads to hyper B cell activation contributing to the development of Sjögren's-like and SLE-like diseases. In support of this, we found that the expanded B cell populations observed in $A c t 1^{-1-}$ spleens were much reduced in Act $1^{-1-} I l 21 r^{-1-}$ mice (Fig. 6a and Supplementary Fig. 4e, f) and Act $1^{-1-} I l 23 r^{-1-}$ mice (Supplementary Fig. 4c), including marginal zone $\mathrm{B}$ cells $\left(\mathrm{B} 220^{+} \mathrm{CD} 21^{\mathrm{hi}} \mathrm{CD} 23^{\mathrm{lo}}\right)$, follicular $\mathrm{B}$ cells $\left(\mathrm{B} 220^{+} \mathrm{CD} 21^{\text {int }} \mathrm{CD} 23^{\mathrm{hi}}\right)$, T1 transitional B cells $\left(\mathrm{B} 220^{+} \mathrm{IgM}^{\mathrm{hi}} \mathrm{C}-\right.$ $\left.\mathrm{D} 21^{\text {low }}\right), \mathrm{T} 2$ transitional $\mathrm{B}$ cells $\left(\mathrm{B} 220^{+} \mathrm{IgM}^{\text {hi }} \mathrm{CD} 21^{+}\right)$, germinal center $\mathrm{B}$ cell $\left(\mathrm{B} 220^{+} \mathrm{GL}^{+} \mathrm{Fas}^{+}\right)$and plasma cell $\left(\mathrm{B} 220^{-} \mathrm{CD} 138^{+}\right)$. To further test this hypothesis, we examined the impact of IL-21 from Th17 cells on B cell proliferation. B220 ${ }^{+}$ $B$ cells and naive $\mathrm{CD} 4^{+} \mathrm{T}$ cells were purified from spleens of wildtype and $\mathrm{Act}^{-/-}$mice. Naive $\mathrm{CD} 4^{+} \mathrm{T}$ cells from wild-type or Act $1^{-/}$mice were polarized to Th17 cells in vitro and added to CFSE-labeled wild-type or Act1 ${ }^{-/-} \mathrm{B} 220^{+}$B cells isolated from spleen of MOG immunized mice in the presence or absence of a blocking anti-IL-21 antibody for 3 days. B cell proliferation was detected by flow cytometry. We found that compared to wild-type Th17 cells, Act1 $1^{-/}$Th17 cells induced more proliferation of both wild-type and $A c t 1^{-/} \mathrm{B}$ cells and that this response was greatly attenuated in the presence of anti-IL-21 antibody (Fig. 6b). We then examined the impact of IL-21 from Th17 cells on antibody production. Wild-type, Act $1^{-/-}$or $A c t 1^{-/-} I L-21 r^{-/-}$B cells isolated from spleen after MOG immunization were co-cultured with wild-type or $A c t 1^{-/-}$Th17 cells in the presence of $\mathrm{MOG}_{35-55}$-peptide, followed by the measurement for antibody production. Again, we found that $A c t 1^{-/}$Th17 cells showed a stronger impact on antibody production compared to wild-type
Th17 cells, and that this effect was significantly blocked by IL-21R deficiency in B cells (Fig. 6c).

Notably, Act1 deficiency in B cells also showed an impact on B cell proliferation and antibody production (Fig. 6b, c). While we have previously reported the regulatory role of Act1 on CD40/ BAFFR signaling, we now wondered whether the Actl's ability to interact with STAT3 has any impact on IL-21-induced STAT3 activation in B cells. We indeed found that Act1 interacted with STAT3 (but not other STATs) in B220+ cells (Supplementary

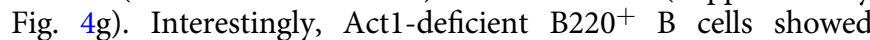
increased IL-21-induced STAT3 phosphorylation (Fig. 6d). Importantly, the IL-21R levels were comparable between wildtype and Act1-deficient B cells (Fig. 6d). On the other hand, the interaction of STAT3 to IL-21R was increased in Act1-deficient (but not Il17ra-, Il17rc-, or Il17rb-deficient) B220 B cells compared to the wild-type cells in response to IL-21 stimulation (Fig. 6e). Consistently, IL-21-enhanced B cell proliferation was increased in Act1-deficient B cells compared to that of wild-type B cells (Supplementary Fig. 4h). Furthermore, wild-type Act1, but not Act1 mutant $(\Delta 300-309$, lost STAT3 interaction), corrected the hyper B cell activation from Act1-deficient spleen in response to IL-21 (Supplementary Fig. 4i). Thus, in addition to the reported regulatory role of Act1 on CD40/BAFFR signaling, Act1 can further suppress B cell function by attenuating IL-21-induced STAT3 activation. Taken together, these results suggest that Th17-derived IL-21 helps to promote T-B cell interaction for B cell expansion and antibody production in Act1-deficient mice (Supplementary Fig. 5). In support of this, we found immunization with $\mathrm{T}$ cell-dependent antigen NP-CGG induced more germinal center formation and plasma cell expansion in Act1deficient mice compared to that of wild-type mice. The impact of Act1 deficiency on $\mathrm{T}$ cell-dependent immune response was attenuated in the $A c t 1^{-/-} I L-21 r^{-/-}$mice (Supplementary Fig. $4 \mathrm{j}, \mathrm{k}$ ).

Anti-IL-21 ameliorates the autoimmunity in Act1 $^{-/-}$mice. We then wondered whether anti-IL-21 neutralizing antibody would be effective in alleviating established disease in $A c t 1^{-/-}$mice. It is important to note that we previously reported Act1-deficient mice in $\mathrm{Balb} / \mathrm{c}$ mice developed SLE- and Sjogren-like disease at the age of 3-4 months ${ }^{5}$. On the other hand, while SLE-like disease was also developed in Act1-deficient C57BL/6J mice around 3-4 months old, Sjogren-like disease phenotypes were only detected in Act1-deficient C57BL/6J mice at much older age (around 7-8 months old). Therefore, for both ex vivo and in vivo experiments, 7-8 months old C57BL/6J mice were used for this study. We decided to examine the therapeutic impact of anti-IL21 on the SLE-like and Sjögren's-like diseases in Act1-deficient $\mathrm{Balb} / \mathrm{c}$ mice. Anti-IL-21 neutralizing antibody was intraperitoneally injected into 4 months old SPF $A c t 1^{-/-}$Balb/c mice every other day for 3 months. Serum autoantibody levels were substantially decreased in $A c t 1^{-/-}$mice treated with the anti-IL21 neutralizing antibody as compared to the isotype control treated mice (Fig. 7a). Antibody deposition and cell infiltration in kidneys and submandibular glands were similarly reduced (Fig. 7b-f), showing that an IL-21 blocking antibody can be used to treat SLE-like disease and Sjögren's-like syndrome in Act1-/mice. These results also indicate that the impact of IL-21 deficiency on the autoimmune phenotype of $A c t 1^{-/}$C57BL/6J mice was confirmed by using anti-IL-21 blockage on Act $1^{-/-} \mathrm{Balb} / \mathrm{c}$ mice. The fact that blockade of IL-21 diminished the $\mathrm{B}$ cell compartment and ameliorated the SLE- and Sjögren's-like diseases in Act1-deficient Balb/c mice indicates that the Th17-IL-21 axis is operative in both strains of mice. The delayed onset of Sjogren-like disease phenotypes in Act1-deficient C57BL/6J mice compared to that of Act1-deficient Balb/c mice could be due to 
a
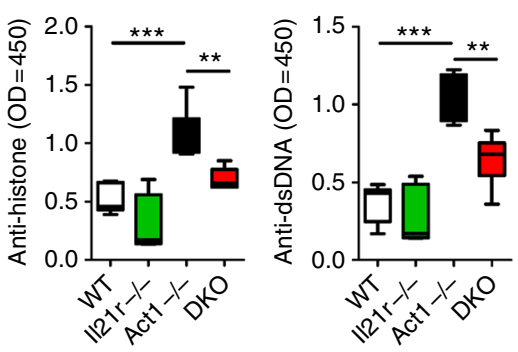

C
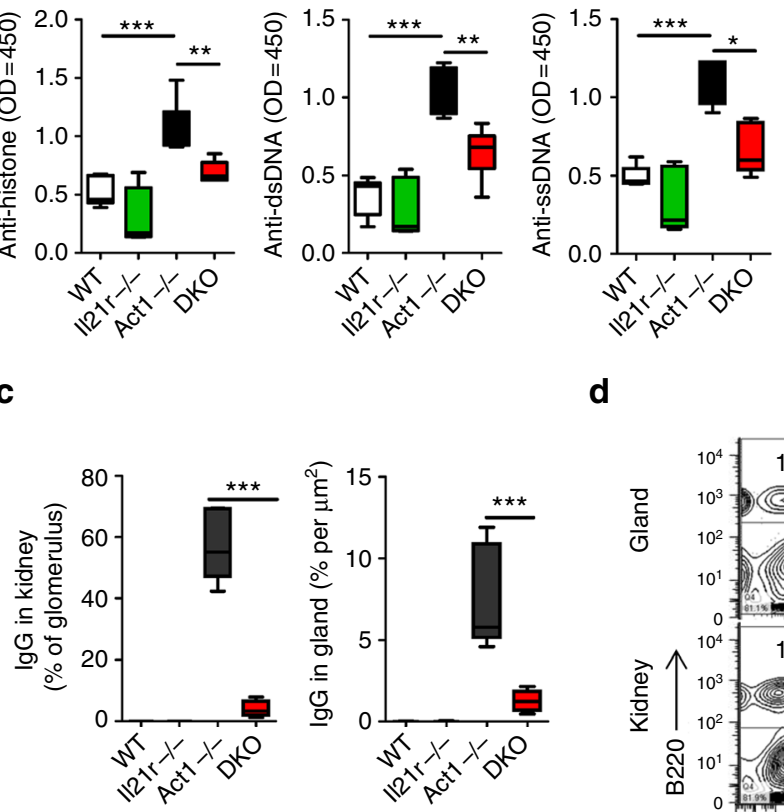

b

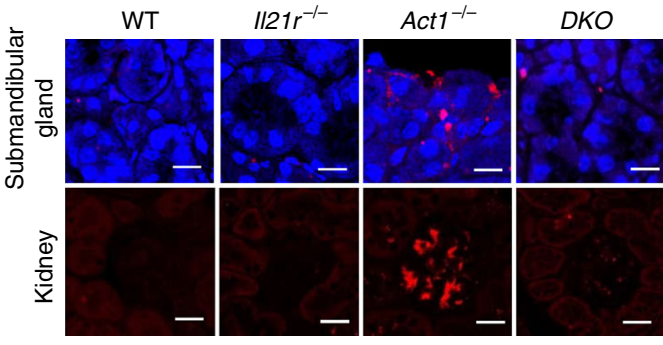

d

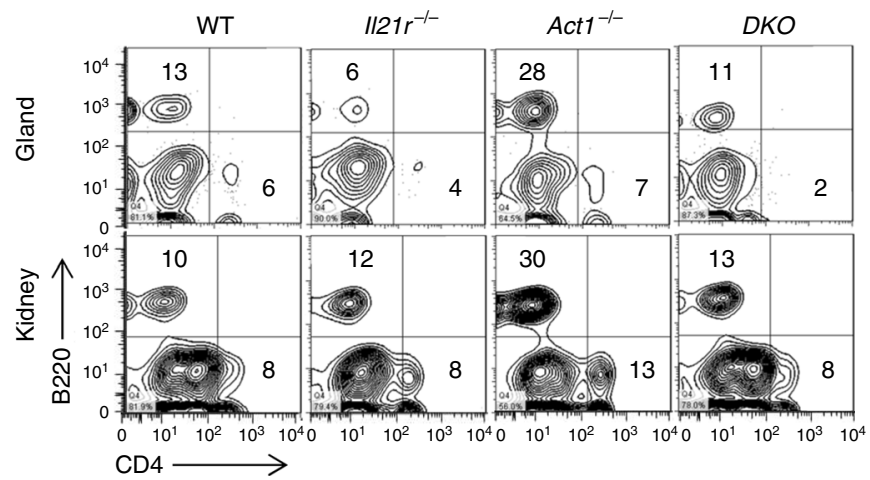

e
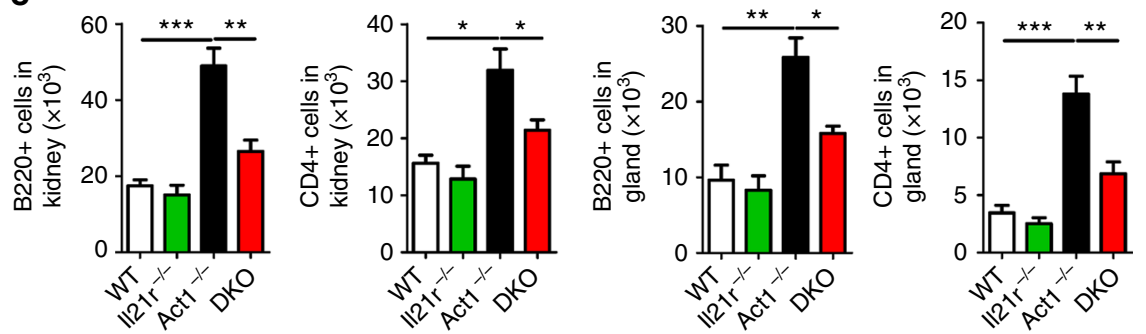

f
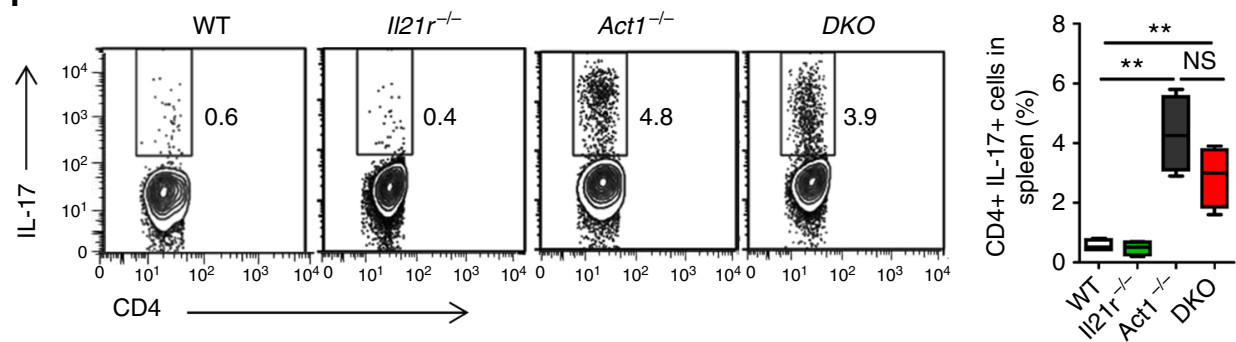

g
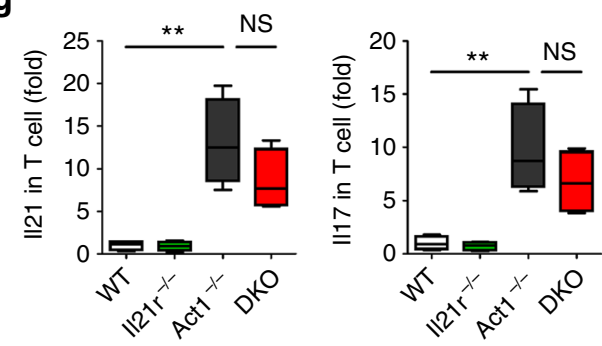

Fig. $5 \mathrm{IL}-21 \mathrm{R}$ required for the autoimmune diseases in Act1-/- mice. All the experiments were performed on C57B/L6J background 7-month-old wild-type

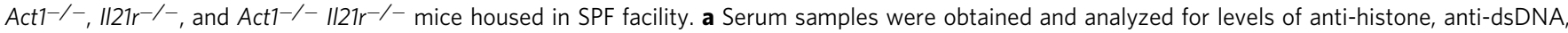
and anti-ssDNA IgG. b Kidneys and submandibular glands were harvested and quick frozen in OCT, followed by immunofluorescence staining for lgG (red). Scale bars, $50 \mu \mathrm{m}$. c Quantification of lgG deposit in glomerulus of kidney and submandibular gland. d, e Flow cytometry analysis of CD45+B220+ and CD45+CD4 ${ }^{+}$cells from kidney and submandibular gland (d) and quantification of $\mathrm{CD} 45^{+} \mathrm{B} 220^{+}$cells and $\mathrm{CD} 45^{+} \mathrm{CD} 4{ }^{+}$cells from submandibular gland and kidney (e). f Flow cytometry analysis of $\mathrm{CD}^{+}{ }^{+} \mathrm{CD} 4^{+}$IL-17A ${ }^{+} \mathrm{T}$ cells from spleen. $\mathbf{g}$ RT-PCR analysis of IL-17 and IL-21 transcripts in CD4 T cells isolated from 8-month-old mice with indicated genotypes. $N=4-7 /$ group. Mean \pm SEM. ${ }^{\star} p<0.05,{ }^{\star \star} p<0.01,{ }^{\star \star *} p<0.001$. Two-tailed Student's $T$ test. All the data presented were from two independent experiments 
a
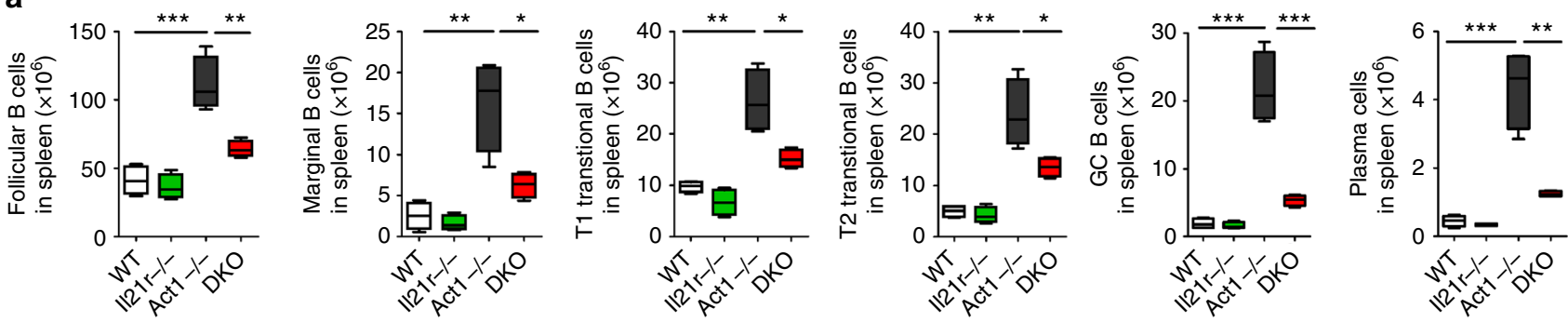

b
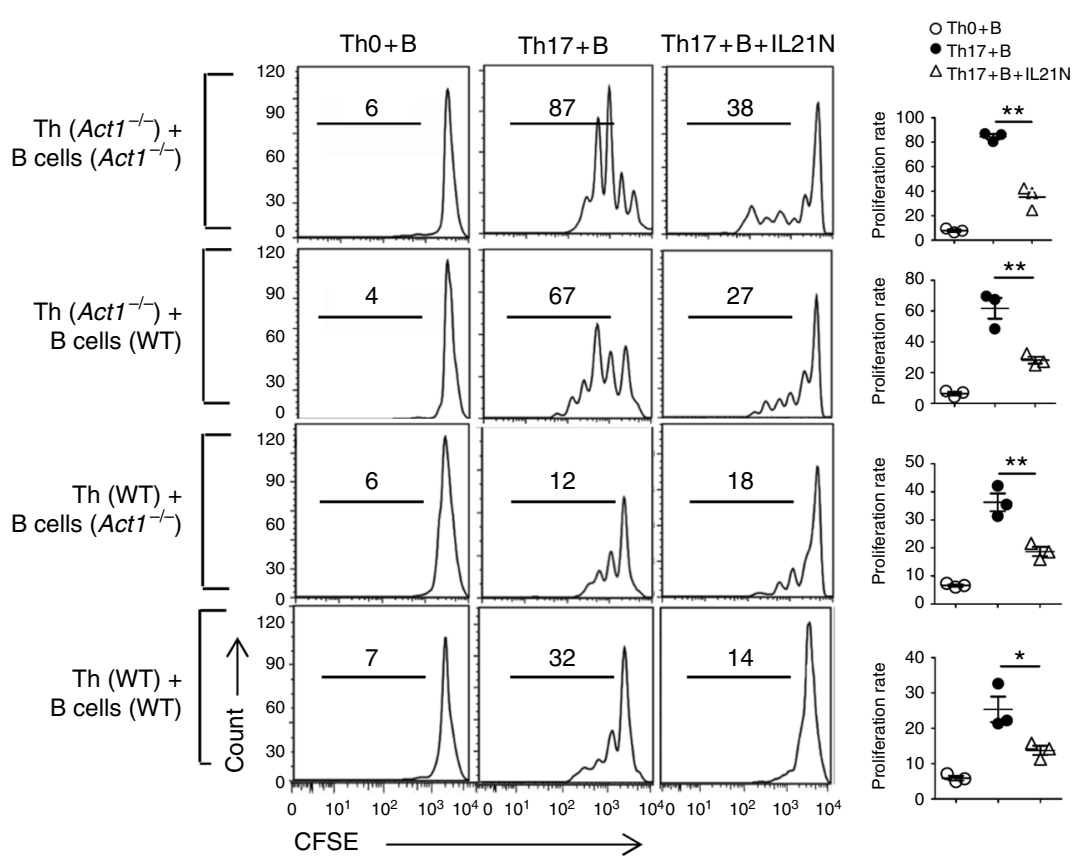

C

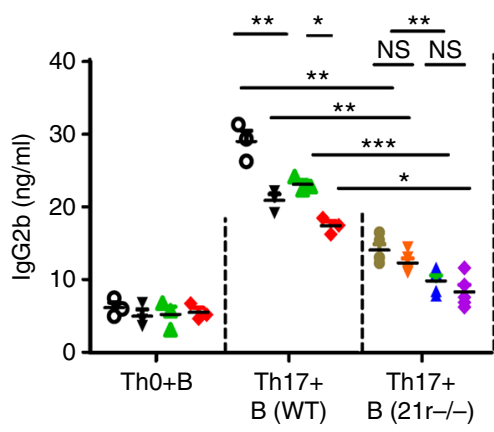

- Act1 $^{-/-}(\mathrm{T})+$ Act1 $^{-/}(\mathrm{B}$ cell $)$

- WT $(\mathrm{T})+\mathrm{Act}^{-1-}(\mathrm{B}$ cell)

$\Delta \mathrm{Act}^{-/-}(\mathrm{T})+\mathrm{WT}$ (B cell)

- WT (T) + WT(B cell)

- $A c t 1^{-/-}(\mathrm{T})+$ Act1 $^{-/-} \| 21 \mathrm{r}^{-/}(\mathrm{B}$ cell $)$

$\checkmark \mathrm{WT}(\mathrm{T})+\mathrm{Act}^{-1-} \| 21 \mathrm{r}^{-/-}$(B cell)

A $\operatorname{Act}^{-1-}(\mathrm{T})+\| 121 \mathrm{r}^{-/-}(\mathrm{B}$ cell $)$

-WT $(T)+\| 21 r^{-1-}(B$ cell $)$

d
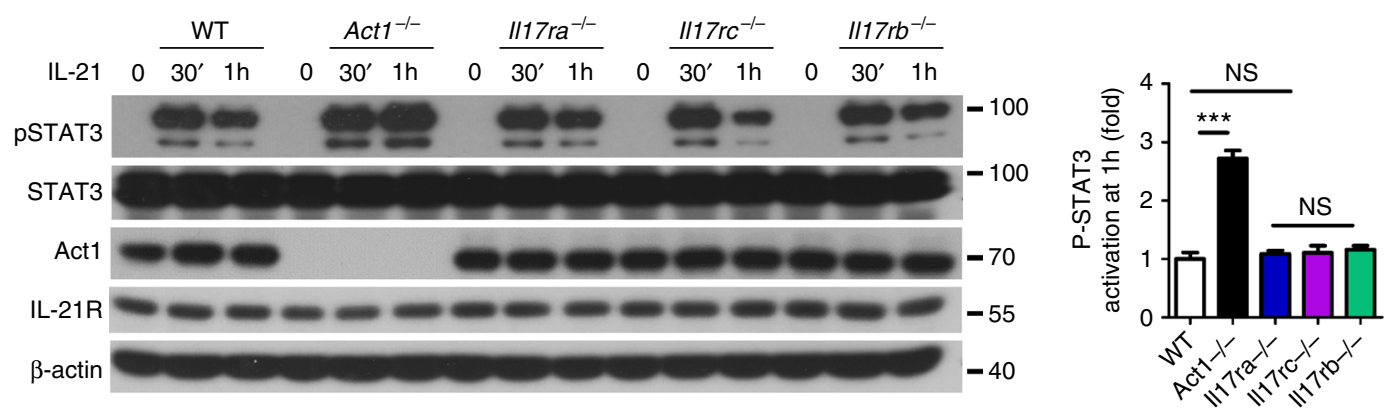

e

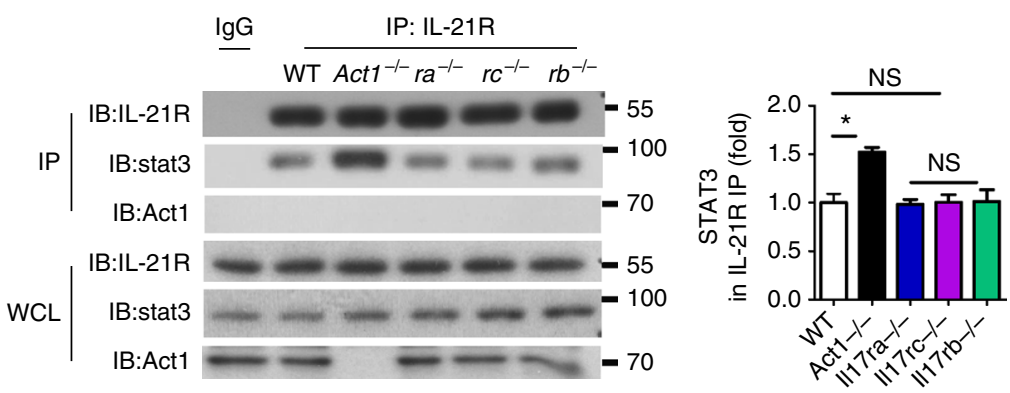

the strain-specific differential immune responses ${ }^{37}$. Future studies are required to further understand the underlining mechanism for this differential Th17 response in these two strains.

We recently investigated the effect of SNP-D10N mutation on the function of Act1 and how SNP-D10N might predispose patients to psoriasis ${ }^{3,21}$. Human ACT1 undergoes alternative splicing so that SNP-D10N results in an amino acid substitution at two different positions of two ACT1 isoforms (variant 1 and variant 2) to generate ACT1-v2-D10N and ACT1-v1-D19N, the latter of which contains nine additional amino acids at the $\mathrm{N}$ 
Fig. 6 IL-21 signaling promotes B cell expansion, antibody production, and T-B cell interaction in Act1-/- mice. a Flow cytometry analysis of marginal zone $B$ cells $\left(B 220^{+} C D 21^{\text {hi }} C D 23^{l o}\right)$, follicular $B$ cells $\left(B 220^{+} C D 21^{\text {int }} C D 23^{\text {hi }}\right), T 1$ transitional $B$ cells $\left(B 220^{+} \mid g M^{\text {hi }} C D 21^{\text {low }}\right)$, T2 transitional B cells

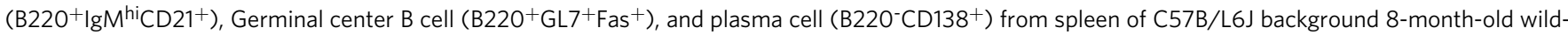
type, Act ${ }^{-/-}, \| 21 r^{-/-}$, and $A c t 1^{-/-} \| 121 r^{-/-}$mice. The graphs indicate the absolute cell numbers in spleen. $\mathbf{b}$ Naive T cells isolated from 6-week-old $M_{35-55}$ immunized wild-type and $A c t 1^{-/-}$mice with indicated phenotypes were cultured with sorted dendritic cells from spleen of same mice in the presence of $\mathrm{MOG}_{35-55}(2 \mu \mathrm{g} / \mathrm{ml})$ under Th0 or Th17-poralizing conditions, followed by co-culturing with CFSE-labeled B220 + B cells isolated from $M_{35-55}$ immunized WT or Act ${ }^{-/}-$mice in the presence of $\mathrm{MOG}_{35-55}(2 \mu \mathrm{g} / \mathrm{ml})$ with or without addition of anti-IL-21 neutralizing antibody. B cell $\left(\mathrm{CD}_{4} 5^{+} \mathrm{B}_{22 \mathrm{O}^{+}}\right.$) proliferation was assessed by CFSE dilution on day 3. c Naive T cells isolated from the indicated 6-week-old $\mathrm{MOG}_{35-55}$ immunized wildtype and $\mathrm{Act1}^{-/-}$mice were cultured with sorted dendritic cells from spleen of same mice in the presence of $\mathrm{MOG}_{35-55}(2 \mu \mathrm{g} / \mathrm{ml})$ under ThO or Th17poralizing conditions, followed by co-culturing with B cells from immunized mice with indicated genotypes in the presence of $\mathrm{MOG}_{35-55}(2 \mu \mathrm{g} / \mathrm{ml})$ for

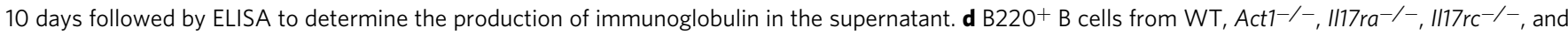
$1117 \mathrm{rb}^{-/-}$mice were stimulated with IL-21 for the indicated times, followed by western blot analysis with the indicated antibodies. STAT3 phosphorylation was quantified as a ratio of phosphorylated-to-total STAT3. Data presented as fold of induction of the cells from knockouts over the wild-type cells. e $\mathrm{B}_{22} \mathrm{O}^{+} \mathrm{B}$ cells were stimulated with IL-21 for $1 \mathrm{~h}$ and immunoprecipitated with anti-IL21R followed by western analysis with anti-STAT3, anti-Act1, and anti-IL21R. STAT3 levels of the immunoprecipitates were quantified as percentage of total STAT3 in the cell lysates. Data presented as fold of induction of the cells from knockouts over the wild-type cells. $N=3-5 /$ group. Mean \pm SEM. ${ }^{\star} p<0.05 ;{ }^{\star} p<0.01$. Two-tailed Student's $T$ test. All the data presented were from two independent experiments

terminus. While ACT1-v2-D10N is non-functional (unable to interact with any of the signaling molecules in the IL-17 pathway), ACT1-v1-D19N retains the ability to interact with signaling molecules and is fully functional ${ }^{3,21}$. ACT1-v1, ACT1v2 and ACT1-v1-D19N were able to interact with STAT3, whereas ACT1-v2-D10N failed to interact with STAT3 (Fig. 7g). In support of this, we found that hyper STAT3 phosphorylation was observed in $\mathrm{ACT} 1^{D 10 N / D 10 N} \mathrm{~T}$ and $\mathrm{B}$ cells in response to IL-6 + IL-23 and IL-21, respectively (Fig. 7h). Importantly, although ACT1-v2-D10N and ACT1-v1-D19N are equally expressed in $\mathrm{ACT} 1^{D 10 N / D 10 N}$ fibroblasts, $\mathrm{ACT} 1^{D 10 N / D 10 N} \mathrm{~T}$ cells express predominantly ACT1-v2-D10N (Fig. 7i, j). As a consequence, ACT1 ${ }^{D 10 N / D 10 N} \mathrm{~T}$ cells behave like Act1-deficient $\mathrm{T}$ cells and exhibit a dysregulated and hyperactive Th17 response. As expected ACT1 1 D10N/D10N and to a lesser extent ACT1 WT/D10N $\mathrm{T}$ cells have elevated $I l 17 a, I l 22$, and $I l 21$ expression as compared to that in control T cells (Fig. 7k). Thus, IL-21 blocking antibody might be an effective therapy for treating SLE-like disease and Sjögren's-like syndrome in patients containing the SNP-D10N mutation.

\section{Discussion}

In this study, we report a novel function of Act1 as a negative regulator in T and B cells via direct inhibition of STAT3, thereby contributing to the development of autoimmune diseases associated with Act1 deficiency. While mass spectrometry analyses identified STAT3 as an Act1-interacting protein, deficiency of Act1 (but not IL-17RA, IL-17RC, or IL-17RB) resulted in hyper IL-23- and IL-21-induced STAT3 activation in T and B cells, respectively. Importantly, deletion of IL-23R signaling $\left(I l 23 r^{-/}\right.$Act $\left.1^{-/-}\right)$ameliorated hyper Th17 response (including Il21 expression) and the Sjögren's and SLE-like diseases in the Act1 ${ }^{-/}-$mice. Although deletion of IL-21R signaling had little impact on the elevated IL-17/IL-21-producing CD4+ T cells (hyper Th17 response) in Act1 ${ }^{-/}$mice, blockade of IL-21 diminished the B cell compartment and ameliorated the SLE- and Sjögren's-like diseases in Act1-deficient mice. These findings indicate that Act1 is a critical checkpoint in immune homeostasis via negative regulation on STAT3 activation during IL-23dependent Th17 response and IL-21-driven B cell function, controlling autoimmunity.

Notably, hyper Th17 responses (increased IL-17 producing $\mathrm{CD}^{+}{ }^{+} \mathrm{T}$ cells) were also observed in IL-17 receptor knockout mice ${ }^{3,22}$, implicating a possible reciprocal relationship between IL-17 signaling and hyper Th17 responses. However, although $\mathrm{IllTr}^{-/-}$and $\mathrm{Il}_{17 \mathrm{ra}^{-}}{ }^{-}$mice developed hyper Th17 cells with elevated Il22 expression and skin inflammation, they did not develop SLE-nephritis and Sjögren's-like disease. Importantly, T cell-specific Act1-deficient mice developed hyper Th17 responses with elevated Il17 and Il21 expression, whereas T cell-specific IL17RC deficiency had no impact on Th17 cells ${ }^{22}$. Here we showed that Act1 interacts with STAT3, which suppresses IL-23-induced STAT3-dependent IL-21 induction and as well as IL-21-mediated STAT3 activation in B cells. Therefore, Act1-mediated negative regulation of $\mathrm{T}$ and $\mathrm{B}$ cell function is probably independent of Actl's role in IL-17 signaling. Since many autoimmune patients are and will be on anti-IL-17 therapy, it is important to segregate the impact of Act1 deficiency versus IL-17 inhibition. Based on our mechanistic studies here, we would not anticipate the SLElike and Sjögren's-like diseases (associated with Act1 deficiency) to be induced in patients under anti-IL-17 therapy.

While Tfh cells are considered as a major source of IL$21^{25,27,34}$, our results suggest that Th17 cells are the major source for increased IL-21 production in Act1-deficient mice. Notably, Th17 cells can acquire features of Tfh cells ${ }^{28-31}$. We indeed found majority of Act1-deficient Th17 cells express markers of Tfh cells including ICOS, PD-1 and Bcl6 $6^{32-36}$. Furthermore, IL-17+ cells were detected inside the $\mathrm{B}$ cell follicles in Act1-deficient spleen, demonstrating the presence of IL-17+ Tfh cells (referred as Tfh17 cells). Tfh 17 cells can serve as effective helper cells, functioning as $\mathrm{B}$-cell helpers in the induction of a proliferative response of $\mathrm{B}$ cells and antibody production ${ }^{28-30}$. Moreover, while we previously reported the regulatory role of Act1 on CD40/BAFFR signaling ${ }^{4}$, we noted here that IL-21-induced STAT3 activation was enhanced in Act1-deficient B cells. Based on these findings, we propose that while Act1 is a necessary signaling molecule for IL-17 signaling, Act1 serves as a negative regulator to modulate Th17-B cell interaction via its impact on IL-23/IL-21/STAT3 axis and CD40, thereby controlling autoimmunity (Supplementary Fig. 5). It is possible that Act1 may inhibit STAT3 activation in response to additional STAT3-activating cytokines. Future studies are required to investigate the spectrum of Actl's inhibitory role on STAT3 activation.

Genome-wide association studies have identified risk variants in the Il21 gene for SLE, psoriasis, and psoriatic arthritis ${ }^{38,39}$. IL21 has been shown to have a pathogenic role in several lupusprone mouse models and its blockade with anti-IL-21 reduced disease progression ${ }^{40-42}$. Furthermore, IL-21 serum levels were shown to positively correlate with disease severity in lupus patients $^{39}$. The fact that either deletion of IL-21R or anti-IL-21 antibody treatment ameliorated the development of Sjögren's and SLE-like diseases in Act1-deficient mice, providing a novel 
a

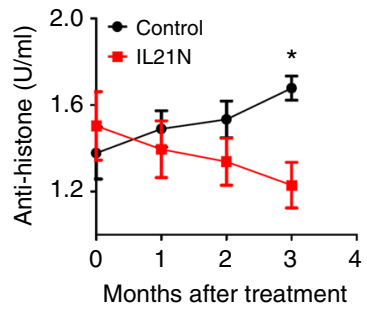

b
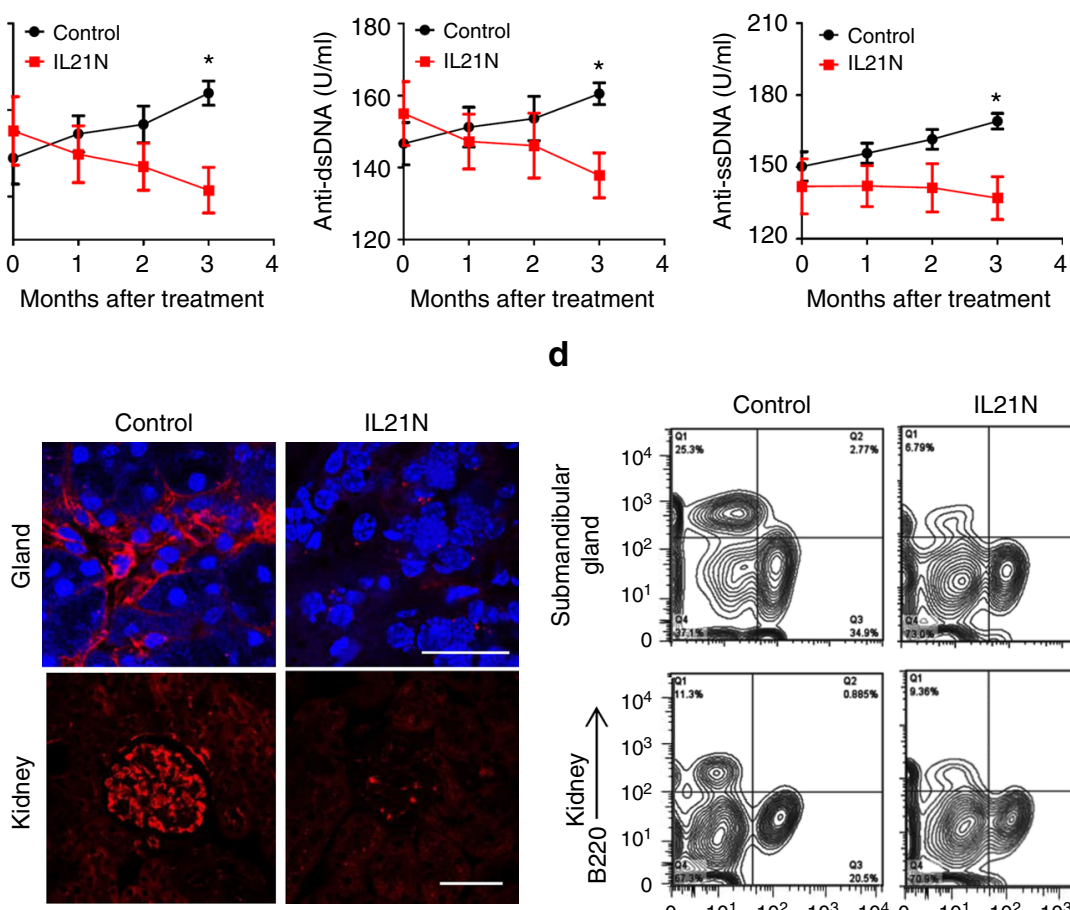

d
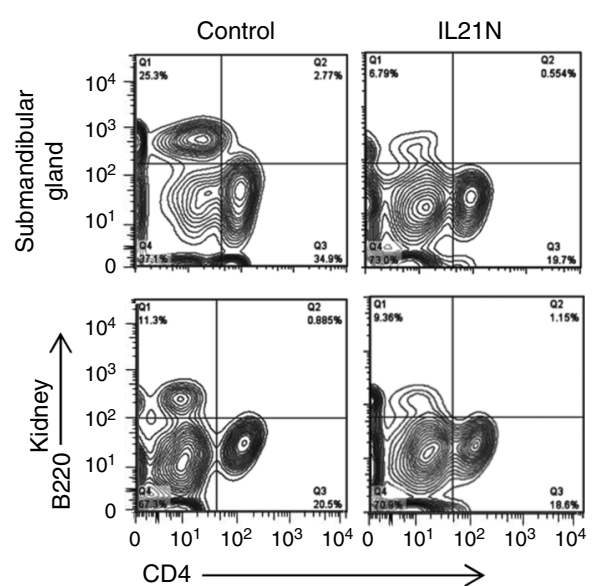

$\mathbf{g}$

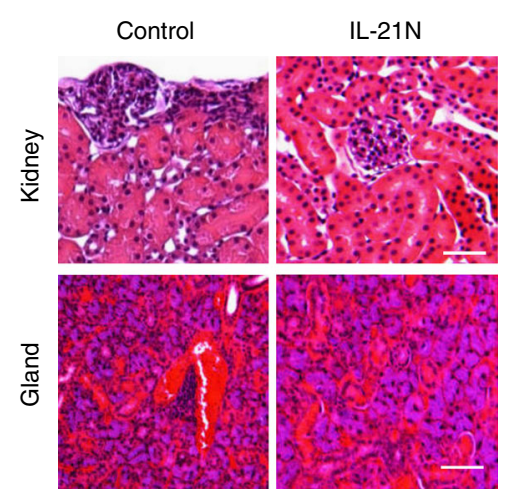

h

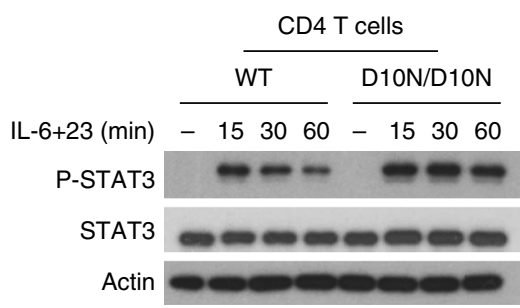

j

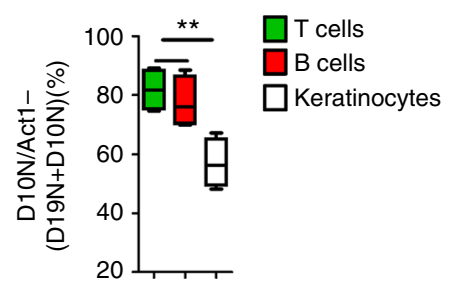

\section{k}

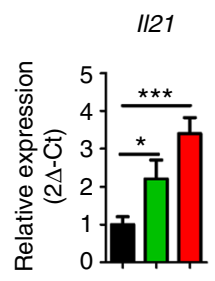

121
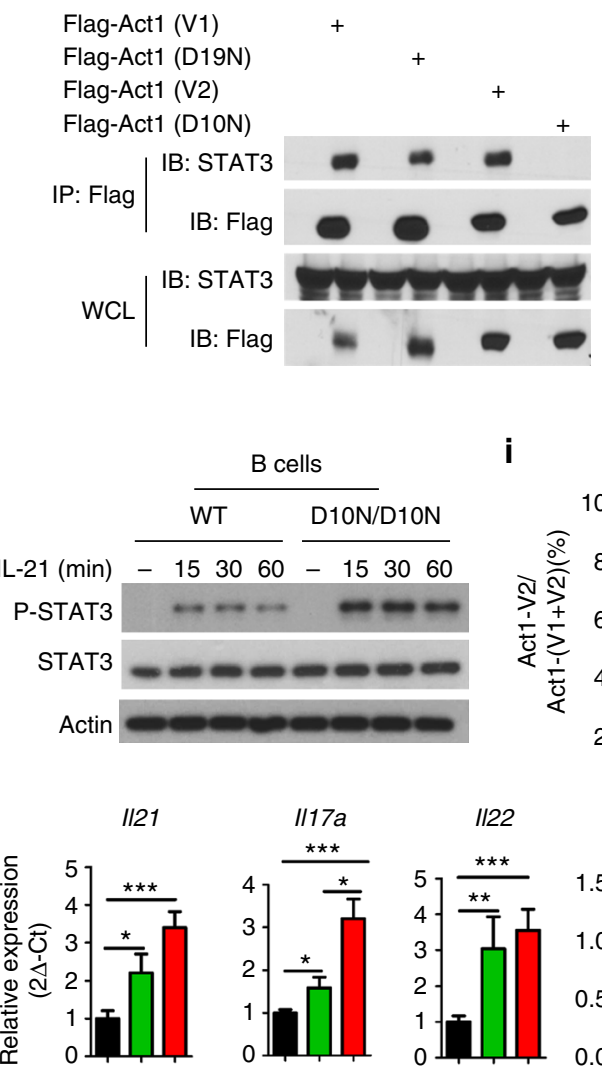
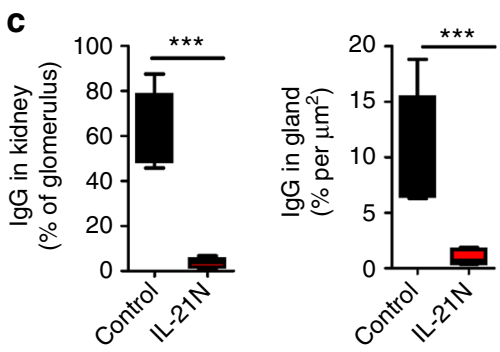

e

$\square$ Control
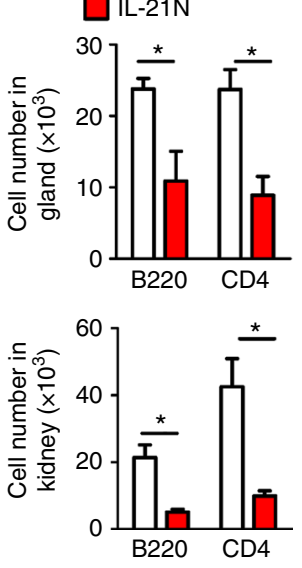
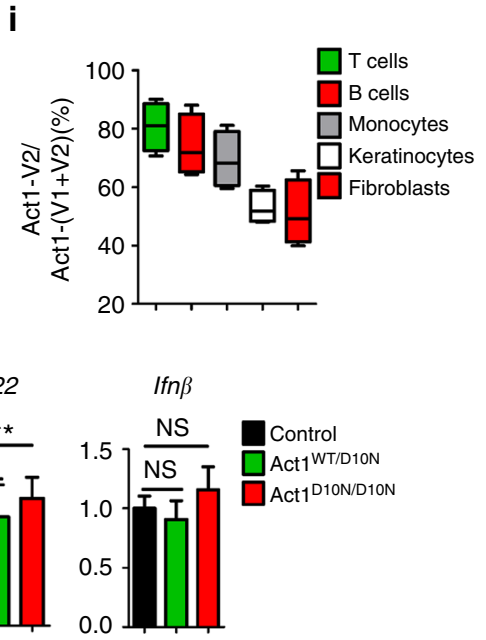
Fig. 7 Neutralization of IL-21 attenuates the autoimmune diseases in Act1-/- mice. 4-month-old SPF Balb/c Act1-/- mice were treated with anti-IL21 or IgG control for additional 3 months. a Serum samples were obtained from Act1-/- mice treated with anti-IL-21 or IgG control and analyzed for levels of anti-histone, anti-dsDNA, anti-ssDNA autoantibodies, and immunoglobulin antibodies. b Kidneys and submandibular glands were harvested and quick frozen in OCT, followed by immunofluorescence staining for lgG (red). Scale bars, $50 \mu \mathrm{m}$. c Quantification of lgG deposit in kidney and gland. d Flow cytometry analysis of $\mathrm{CD} 45^{+} \mathrm{B} 22 \mathrm{O}^{+}$cells and $\mathrm{CD} 45^{+} \mathrm{CD} 4^{+}$cells from kidney and submandibular gland of SPF Act1-/- mice treated with anti-IL-21 or IgG control. e Quantification of CD45+B220+ cells and CD45+CD4+ cells from submandibular gland and kidney. f Frozen section of kidney and gland from SPF mice were stained with H\&E. $\mathbf{g}$ The indicated Act1 variants were transfected into HeLa cells, followed by co-immunoprecipitation and western analyses with the indicated antibodies. $\mathbf{h}$ Western blot analysis of IL-6 + IL-23-induced p-STAT3 in CD4+ T cells and IL-21-induced p-STAT3 in B cells from $\mathrm{ACT1}$ WT/WT or ACT1D10N/D10N. i, j RT-PCR analysis of ACT1-v1 and ACT1-v2 in indicated human cells from control donors (i) or T, B cells and fibroblasts from an ACT1D10N/D10N patient (j). k RT-PCR analysis of $I 117 a,\|122\|$,121 , and Ifn $\beta$ expression in human PBMCs from controls, ACT1WT/D10N or ACT1D10N/D10N individuals $A C T 1{ }^{D 10 N / D 10 N}$ patients. $N=4-6 /$ group. ${ }^{\star} p<0.05,{ }^{\star \star} p<0.01,{ }^{\star \star \star} p<0.001$. Two-tailed Student's $T$ test. All the data presented were from two independent experiments

mechanism for the association of IL-21 with these autoimmune phenotypes. Importantly, TRAF3IP2 (coding for Act1) polymorphisms [rs33980500 (Act1-D10N) and rs13193677] were reported to have significant association with SLE susceptibility $(p$ $=0.021$, odds ratio $(\mathrm{OR})=1.71$, and $p=0.046, \mathrm{OR}=1.73$, respectively). While rs13193677 was reported in 15\% lupus patients, 21.3\% SLE patients contain rs33980500 (Act1-D10N), indicating a strong association between Act1 mutation (loss of function) and human lupus disease ${ }^{17}$. Moreover, Act1 expression was shown to be reduced in B cells from patients with Sjögren's disease ${ }^{43}$. Therefore, the Act1-deficient mice represent a mouse model for lupus and SLE patients carrying Actl mutations. Notably, although anti-IL-21 also attenuated disease in other lupus-prone mouse models, Act1 levels were not reduced in those lupus mice, indicating that IL-21 is probably modulated by multiple pathways. Moreover, hyper Th17 response (with increased IL-17/IL-21 producing CD4 ${ }^{+} \mathrm{T}$ cells) is not observed in all of the lupus-prone mice. Considering the heterogeneity of lupus patients, the efficacy of anti-IL-21 antibody on Act1deficient mice implicates that this mouse strain can be further exploited as a specific model for testing anti-IL-21 as a potential therapy for SLE patients with the SNP-D10N Act1 mutation.

\footnotetext{
Methods

Mice. Il23r $r^{-/-}$and $A c t 1^{-/-}$mice were generated in our lab ${ }^{3,4} .{I l 21 r^{-/-}}$mouse was a gift from Dr. Warren J. Leonard, Molecular Immunology Department of NIH. Act ${ }^{-/-} I l 23 r^{-/-}$and $A c t 1^{-/-} I l 21 r^{-/-}$mice on C57BL/6 background were generated and maintained at Cleveland Clinic. All the mice used in this study were C57BL/6 background females housed in SPF facility and sacrificed for analysis at the age of 8-month-old unless we indicate otherwise. All animal experiments conducted were approved by Cleveland Clinic Institutional Animal Care and Use Committee.
}

Human sample collection. The human PBMC were collected from NeckerEnfants Malades Hospital and Cleveland Clinic. Informed consent was obtained from all subjects. This study was approved by local ethics committee of the Rockefeller University Hospital and Cleveland Clinic. The genotyping was conducted by RT-PCR using specific Act1-D10N probes ${ }^{44}$.

Reagents. The following antibodies were from eBioscience: rat anti-mouse CD4 (1:400, RM4-5), rat anti-mouse CD44 (1:400, IM7), rat anti-mouse IFN $\gamma$ (1:500, XMG1.2), rat anti-mouse CD8 (1:400, 53-6.7), rat anti-mouse lgM (1:400, 11/41), rat anti-mouse IL-4 (1:500, 11b11), rat anti-mouse IL-21 (1:500, mhalx21), hamster anti-mousePD1 (1:500, J43). The following antibodies were from Biolegend: rat anti-mouse IL17A (1:400, TC11-18H10), rat anti-mouse Bcl6 (1:400,7D1), mouse anti-mouse Fas (1:400, SA367H8), rat anti-mouse CD138 (1:400, 281-2), hamster anti-mouse CD3 (1:400, 145-2c11), rat anti-mouse B220 (1:600, RA3-6B2), rat anti-mouse CD45 (1:2000, 30-F11), hamster anti-mouse ICOS (1:400, C398.4A), rat anti-mouse CXCR5 (1:500, L138D7). The following antibodies were from BD: rat anti-mouse CD23 (1:500, B3B4), rat anti-mouse CD21 (1:500, 7G6), rat antimouse IL-4 (for cell culture,1:1000, 11B11, cat: 554432), rat anti-mouse IFN $\gamma$ (for cell culture,1:1000, XMG1.2, cat: 559065), purified NA/LE hamster anti-mouse CD3e (1:500, 145-2C11, cat: 553057) and purified NA/LE hamster anti-mouse CD28 (1:500, 37.51, cat: 553294). Rabbit Anti-mouse/human STAT3 (1;1000, D3Z2G, cat: 12640S), Stat Antibody Sampler Kit II (1:1000, Cat: 93130), rabbit anti-mouse p-STAT1 (Tyr701) (1:1000, 58D6, Cat: 9167S), rabbit anti-mouse pSTAT5 (Tyr694) (1:1000, D47E7, Cat:4322T), rabbit anti-mouse p-STAT6 (Tyr641)(1:1000, D8S9Y, Cat: 56554S), rabbit anti-mouse/human Phospho-STAT3
(Tyr705) (1:1000, Cat: 9131L), rabbit anti-HA (1:1000, C29F4 cat: 3724S) and rabbit anti-flag (1:1000, cat: 2368s) were from Cell Signaling Technology. Mouse anti-HA (1:1000, clone HA-7), mouse anti-M2 (1:1000, clone M2) were from Sigma. Rat anti-mouse GL7 antibody (1:200, GL-7, Cat: 13-5902-81) was brought from Thermo Fisher. Goat anti-Peanut Agglutinin (PNA, 1:100, AS2074) was from Vector lab. Rabbit anti-mouse IL-12Rb1 (1:1000, Cat: 97813), rabbit anti-mouse pSTAT2 (Y690) (1:1000, Cat: 53132) and rabbit anti-mouse p-STAT4 (Y693) (1:1000, Cat: 28815) were from Abcam. Goat anti-mouse/human $\beta$-Actin was from Santa Cruze (1:1000, C-2). Recombinant mouse IL-6 protein (406-ML-005) and recombinant mouse IL-23 Protein (1887-ML-010) were from R\&D. CFSE (1:2000, cat: C34554) was from Molecular Probes. Horse anti-mouse lgG $(\mathrm{H}+\mathrm{L})$ (for immunofluorescence staining, 1:300, cat: TI-2000) was from Vector laboratories, Inc. Rat anti-mouse TureBlot antibody (1:1000, eB144) and mouse anti-rabbit TureBlot antibody (1:1000, eB182).

Cell surface and intracellular staining. For intracellular staining, single-cell suspensions obtained from the spleen, kidney, and submandibular gland of mice were cultured for $5 \mathrm{~h}$ with phorbol 12-myristate 13-acetate (PMA, $20 \mathrm{ng} / \mathrm{ml}$, Sigma) plus ionomycin (500 ng/ml, Sigma). GolgiStop (1:500, BD Biosciences) was added during the final $2 \mathrm{~h}$ of incubation. Cells were stained with cell surface antibody for $30 \mathrm{~min}$ at $4{ }^{\circ} \mathrm{C}$ followed with fixation/permeabilization solution (BD Cytofix/ Cytoperm $^{\text {Tx }}$ Kit) according to the manufacturer's instructions. After washing three times with Perm/Wash buffer, antibodies for intracellular staining were added for $1 \mathrm{~h}$ at $4{ }^{\circ} \mathrm{C}$ and cells were analyzed on a FACSCalibur (BD).

Quantitative real-time PCR. Mice were perfused with $1 \times$ PBS. Kidneys and glands were harvested and homogenized with an OMNI TH tissue homogenizer (Omni International) and total RNA was extracted using TRIzol reagent according to the manufacturer's instructions (Invitrogen). The cDNA was synthesized with Oligo (dT) primers and superscript II reverse transcriptase (Invitrogen) by using $1 \mu \mathrm{g}$ total RNA. The cDNA was resuspended in $100 \mu \mathrm{l}$ of $\mathrm{H}_{2} \mathrm{O}$, and $2 \mu \mathrm{l}$ of cDNA samples were used for real-time PCR in a total volume of $20 \mu \mathrm{l}$ of SYBR Green reagent (Invitrogen) and specific primers. All gene expression results are expressed as arbitrary units relative to the expression of $\beta$-actin. The following RT-PCR primers ordered from Invitrogen were used for mouse genes: Il21, 5' CCCTTGTCTGTCTGGTAGTCATC- $3^{\prime}$ and $5^{\prime}$-ATCACAGGAAGGGCATTTAG C-3'; $B c l 2,5^{\prime}$-GGAAGGTAGTGTGTGTGG-3' and $5^{\prime}$-ACTCCACTCTCTGGGT TCTTGG-3'; $B c l x l, 5^{\prime}$-GCTGGGACACTTTTGTGGAT-3' and $5^{\prime}$-TGTCTGGTC ACTTCCGACTG-3'; $\beta$-actin, $5^{\prime}$ - AGATGTGGATCAGCAAGCAG-3' and $5^{\prime}-$ GCGCAAGTTAGGTTTTGTCA-3'; Il17a, 5'-GTCCAGGGAGAGCTTCATC TG-3' and 5'-CTTGGCCTCAGTGTTTGGAC-3'; Sox5, 5'-GAACAGCATAGG TCTCAGCCAC- $3^{\prime}$ and $5^{\prime}$-CATGGCTAAATTTCCCTTCTTC-3'; Ror $\gamma t, 5^{\prime}$ CCATTCAGTATGTGGTGGAGTT- ${ }^{\prime}$ and $5^{\prime}$-CTGACTAGGACGACTTCCAT TG-3'.

Histology and immunostaining. Tissues were immediately frozen in OTC embedding media and were sectioned or serially sectioned to obtain consecutive slices. Sections were stained with anti-lgG dsRed $(\mathrm{H}+\mathrm{L})$ and DAPI. All images were captured with a DP71 digital camera (Olympus) attached to an Olympus BX41 microscope.

Antibodies and autoantibodies measurement. Serum IgM, IgG1, IgG2a, IgG2b, IgG3, IgA, Anti-histone IgG, anti-dsDNA, and anti-ssDNA were detected using ELISA kits. 96-well plates were coated with $50-100 \mu \mathrm{L}$ capture antibodies for overnight at $4{ }^{\circ} \mathrm{C}$ or $2 \mathrm{~h}$ in room temperature following the manufacturer's instruction. Wash wells four times using an automated 96-well plate washer and add $100 \mu \mathrm{L}$ diluted serum or standards incubating at room temperature for $2 \mathrm{~h}$. Wash wells four times and add $100 \mu \mathrm{L}$ of diluted detection antibody to each well incubating for $1 \mathrm{~h}$. After washing, add $100 \mu \mathrm{L}$ of diluted HRP conjugate to each well for $30 \mathrm{~min}$. Thoroughly aspirate and add $100 \mu \mathrm{L}$ of substrate to each well and develop plate at room temperature in the dark for $30 \mathrm{~min}$. Stop the reaction by adding $100 \mu \mathrm{L}$ of stop solution. While the levels of Ig isotypes were read at $405 \mathrm{~nm}$, 
the levels of autoantibodies were read at $450 \mathrm{~nm}$. The antibody concentrations were calculated using Ig standards, provided by the manufacturer.

Anti-IL21 antibody treatment in vivo. Anti-IL-21 antibody was obtained from Dr. Ken Coppieters, Principal Scientist in Novo Nordisk A/S. Act1-deficient were treated with anti-IL-21 neutralizing antibody intraperitoneally at $0.5 \mathrm{mg} / \mathrm{mouse}$ every other day for 3 months. Serum was collected monthly to assess the levels of autoantibodies (anti-histone lgG, anti-dsDNA, and anti-ssDNA) and immunoglobulin isotypes.

Retroviral and lentiviral production. For infection of Naive T cells and B cells viral supernatant were collected $36 \mathrm{~h}$ after transfection of Phoenix cells (ATCC, ATCC $^{\circledR}$ Number: CRL-3213 ${ }^{\text {rx }}$ ) with $5 \mu$ g sequence encoding HA-tagged Act1 or Actl mutant ( $\triangle 300-309)$ cloned into pMSCV-pBabeMCS-IRES-RFP (Addgene plasmid \# 33337). ATCC reported to use morphology, karyotyping, and PCR-based approaches to confirm the identity. Plasmocin was used to rule out the contamination during the cell culture. For knockdown Actl gene in naive T cells, shRNA plasmids ordered from Sigma (TRCN0000105990 and TRCN0000105992) were transduced into Phoenix cells and viral supernatant were collected $36 \mathrm{~h}$ after transfection.

In vitro T cell polarization. Cell suspensions from spleens were prepared as described before. For in vitro Th17 polarization, $\mathrm{CD} 3{ }^{+} \mathrm{CD} 4{ }^{+} \mathrm{CD} 44^{\text {low }}$ naive $\mathrm{T}$ cells were sorted by flow cytometry and cultured in 24-well plates coated with anti-CD3 $(1 \mu \mathrm{g} / \mathrm{ml}, \mathrm{BD})$ and anti-CD28 $(2 \mu \mathrm{g} / \mathrm{ml}, \mathrm{BD})$ for 3 days. For Th0 polarization, antiIFN $\gamma(10 \mu \mathrm{g} / \mathrm{ml})$ and anti-IL-4 $(10 \mu \mathrm{g} / \mathrm{ml})$ neutralizing antibodies were added to the culture. For Th17 polarization, anti-IFN $\gamma(10 \mu \mathrm{g} / \mathrm{ml})$ and anti-IL-4 $(10 \mu \mathrm{g} / \mathrm{ml})$ neutralizing antibodies, IL-6 $(10 \mathrm{ng} / \mathrm{ml})$ and IL-23 $(10 \mathrm{ng} / \mathrm{ml})$ were added to the culture. To generate antigen-specific Th17 cells for Th17 and B cell co-culture, Naive $\mathrm{T}$ cells were isolated from $\mathrm{MoG}_{35-55}$ immunized mice and polarized in the presence of the cytokines above with additional $\mathrm{MOG}_{35-55}$ peptide and sorted dendritic cells which were also isolated from $\mathrm{MOG}_{35-55}$ immunized mice. The purity of Th17 cells were determined by flow cytometry in 3-5 days.

B cell differentiation (CFSE). B220 ${ }^{+}$cells were sorted by flow cytometry from spleen of $\mathrm{MOG}_{35-55}$ immunized WT and $A c t 1^{-/-}$mice and suspended in PBS (1 $10^{7} / \mathrm{ml}$ ). Subsequently, $2 \times$ CFSE dye (Molecular Probe) was added to a final concentration of $2.5 \mu \mathrm{M} / \mathrm{ml}$. After incubation for $7 \mathrm{~min}$ at room temperature, cells were washed with cold DMEM media with $10 \%$ FBS for three times and cocultured with Th0, Th17 cells plus MOG $_{35-55}$ peptide $(2 \mathrm{ng} / \mathrm{ml})$, anti-IFN $\gamma$ $(10 \mu \mathrm{g} / \mathrm{ml})$, anti-IL-4 $(10 \mu \mathrm{g} / \mathrm{ml})$ with and without anti-IL21 neutralization antibody $(10 \mu \mathrm{g} / \mathrm{ml})$. On day 3 , cells were stained with antibodies against cell surface markers CD4 and B220 followed by flow cytometry analysis.

Th17 induced antibody production in vitro. Sorted $\mathrm{B} 220^{+}$cells from spleens of WT, $A c t 1^{-/-}, I l 21 r^{-/-}$, and Act $1^{-/-} I l 21 r^{-/-}$mice (C57BL/6 background) were cocultured with Th0 or differentiated Th17 cells in U-bottom 96 plates plus MOG 35 ${ }_{55}$ peptide $(2 \mathrm{ng} / \mathrm{ml})$, anti-IFN $\gamma(10 \mu \mathrm{g} / \mathrm{ml})$ and anti-IL- $4(10 \mu \mathrm{g} / \mathrm{ml})$ for 10 days. The supernatants of the culture were analyzed for immunoglobulin isotypes.

Immunoblotting and immunoprecipitation. HeLa cell line $\left(\right.$ ATCC $^{\circledR}$ CCL- ${ }^{\text {ix }}$ ) was brought from ATCC and it reported to use morphology, karyotyping, and PCRbased approaches to confirm the identity. Plasmocin was used to rule out the contamination during the cell culture. Cells were lysed in lysis buffer $(0.5 \%$ Triton X-100, 20 mM HEPES, pH 7.4, $150 \mathrm{mM} \mathrm{NaCl}, 12.5 \mathrm{mM} \beta$-glycerophosphate, 1.5

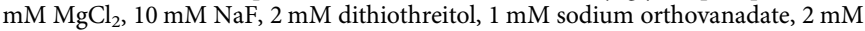
EGTA, $20 \mathrm{mM}$ aprotinin, $1 \mathrm{mM}$ phenylmethylsulfonyl fluoride). Twenty micrograms of protein lysate was run per lane on a $12 \%$ SDS-PAGE gel and subjected to immunoblotting with different antibodies. Co-immunoprecipitation experiments were performed as described previously ${ }^{3}$.

Proximity ligation assay. Direct Act1 and STAT3 protein interaction was assessed by a proximity ligation assay following the instructions of Duolink in Situ Fluorescence Kit (Sigma). HeLa cells were transfected with V5-tagged Actl and Flagtagged stat 3 plasmids for 3 days and washed with cold washing buffer followed by fixation at room temperature for $5 \mathrm{~min}$ in $2 \%$ paraformaldehyde. After washing three times, blocking buffer containing $0.1 \%$ Triton X-100, $5 \%$ goat serum and $3 \%$ $\mathrm{H}_{2} \mathrm{O}_{2}$ was performed to allow permeabilization at $37^{\circ} \mathrm{C}$ for $1 \mathrm{~h}$. Cells were further incubated with primary antibodies (mouse anti-V5, rabbit anti-FLAG; Sigma), secondary antibodies (anti-rabbit PLUS and anti-mouse MINUS) and green detection reagent. The steps of incubation, ligation, and amplification were all performed following manufacturer instructions.

Statistical analysis. Two-tailed Student's $T$ test was performed to determine the significance of differences between two groups. All results were demonstrated as mean \pm SEM. ${ }^{*} p<0.05 ;{ }^{* *} p<0.01 ;{ }^{* * *} p<0.001$. All data were from at least two independent experiments.
Data availability. All relevant data are available from the authors.

Received: 30 August 2017 Accepted: 23 May 2018

Published online: 16 July 2018

\section{References}

1. Tsokos, G. C. Systemic lupus erythematosus. N. Engl. J. Med. 365, 2110-2121 (2011).

2. Bertsias, G. K. \& Boumpas, D. T. Pathogenesis, diagnosis and management of neuropsychiatric SLE manifestations. Nat. Rev. Rheumatol. 6, 358-367 (2010).

3. Wang, C. et al. The psoriasis-associated D10N variant of the adaptor Act1 with impaired regulation by the molecular chaperone hsp90. Nat. Immunol. 14, 72-81 (2013).

4. Qian, Y. et al. Act1, a negative regulator in CD40- and BAFF-mediated B cell survival. Immunity 21, 575-587 (2004).

5. Qian, Y. et al. Deficiency of Act1, a critical modulator of B cell function, leads to development of Sjogren's syndrome. Eur. J. Immunol. 38, 2219-2228 (2008).

6. Johnson, A. C. et al. Lack of T cells in Act1-deficient mice results in elevated IgM-specific autoantibodies but reduced lupus-like disease. Eur. J. Immunol. 42, 1695-1705 (2012).

7. Annunziato, F., Cosmi, L., Liotta, F., Maggi, E. \& Romagnani, S. Type 17 T helper cells-origins, features and possible roles in rheumatic disease. Nat. Rev. Rheumatol. 5, 325-331 (2009).

8. Miossec, P. \& Kolls, J. K. Targeting IL-17 and TH17 cells in chronic inflammation. Nat. Rev. Drug Discov. 11, 763-776 (2012)

9. Moriyama, M. et al. T helper subsets in Sjogren's syndrome and IgG4-related dacryoadenitis and sialoadenitis: a critical review. J. Autoimmun. 51, 81-88 (2014).

10. Qian, Y. et al. The adaptor Act1 is required for interleukin 17-dependent signaling associated with autoimmune and inflammatory disease. Nat. Immunol. 8, 247-256 (2007).

11. Li, X. et al. Act1, an NF-kappa B-activating protein. Proc. Natl Acad. Sci. USA 97, 10489-10493 (2000).

12. Gaffen, S. L., Jain, R., Garg, A. V. \& Cua, D. J. The IL-23-IL-17 immune axis: from mechanisms to therapeutic testing. Nat. Rev. Immunol. 14, 585-600 (2014).

13. Zepp, J., Wu, L. \& Li, X. IL-17 receptor signaling and Thelper 17-mediated autoimmune demyelinating disease. Trends Immunol. 32, 232-239 (2011).

14. Kang, Z. et al. Act1 mediates IL-17-induced EAE pathogenesis selectively in NG2+ glial cells. Nat. Neurosci. 16, 1401-1408 (2013).

15. Swaidani, S. et al. The critical role of epithelial-derived Act1 in IL-17- and IL-25-mediated pulmonary inflammation. J. Immunol. 182, 1631-1640 (2009).

16. Claudio, E. et al. The adaptor protein CIKS/Act1 is essential for IL-25mediated allergic airway inflammation. J. Immunol. 182, 1617-1630 (2009).

17. Perricone, C. et al. TRAF3IP2 gene and systemic lupus erythematosus: association with disease susceptibility and pericarditis development. Immunogenetics 65, 703-709 (2013).

18. Genetic Analysis of Psoriasis Consortium et al. A genome-wide association study identifies new psoriasis susceptibility loci and an interaction between HLA-C and ERAP1. Nat. Genet. 42, 985-990 (2010).

19. Ellinghaus, E. et al. Genome-wide association study identifies a psoriasis susceptibility locus at TRAF3IP2. Nat. Genet. 42, 991-995 (2010).

20. Huffmeier, U. et al. Common variants at TRAF3IP2 are associated with susceptibility to psoriatic arthritis and psoriasis. Nat. Genet. 42, 996-999 (2010).

21. $\mathrm{Wu}, \mathrm{L}$. et al. The differential regulation of human ACT1 isoforms by Hsp90 in IL-17 signaling. J. Immunol. 193, 1590-1599 (2014).

22. Kumar, P. et al. Intestinal interleukin-17 receptor signaling mediates reciprocal control of the gut microbiota and autoimmune inflammation. Immunity 44, 659-671 (2016).

23. Kimura, A. \& Kishimoto, T. IL-6: regulator of Treg/Th17 balance. Eur. J. Immunol. 40, 1830-1835 (2010).

24. Korn, T., Bettelli, E., Oukka, M. \& Kuchroo, V. K. IL-17 and Th17 Cells. Annu. Rev. Immunol. 27, 485-517 (2009).

25. Luthje, K. et al. The development and fate of follicular helper $\mathrm{T}$ cells defined by an IL-21 reporter mouse. Nat. Immunol. 13, 491-498 (2012).

26. Spolski, R. \& Leonard, W. J. IL-21 and T follicular helper cells. Int. Immunol. 22, 7-12 (2010)

27. Ma, C. S., Deenick, E. K., Batten, M. \& Tangye, S. G. The origins, function, and regulation of T follicular helper cells. J. Exp. Med. 209, 1241-1253 (2012).

28. Mitsdoerffer, M. et al. Proinflammatory T helper type 17 cells are effective B cell helpers. Proc. Natl Acad. Sci. USA 107, 14292-14297 (2010). 
29. Yang, Y. et al. High frequencies of circulating Tfh-Th17 cells in myasthenia gravis patients. Neurol. Sci. 38, 1599-1608 (2017).

30. Pfeifle, R. et al. Regulation of autoantibody activity by the IL-23-TH17 axis determines the onset of autoimmune disease. Nat. Immunol. 18, 104-113 (2017).

31. Zhang, C. J. et al. Augmentation of circulating follicular helper T cells and their impact on autoreactive B cells in myasthenia gravis. J. Immunol. 197, 2610-2617 (2016).

32. Weber, J. P. et al. ICOS maintains the T follicular helper cell phenotype by down-regulating Kruppel-like factor 2. J. Exp. Med. 212, 217-233 (2015).

33. Stone, E. L. et al. ICOS coreceptor signaling inactivates the transcription factor FOXO1 to promote Tfh cell differentiation. Immunity 42, 239-251 (2015).

34. Crotty, $\mathrm{S}$. T follicular helper cell differentiation, function, and roles in disease. Immunity 41, 529-542 (2014).

35. Deenick, E. K. \& Ma, C. S. The regulation and role of T follicular helper cells in immunity. Immunology 134, 361-367 (2011).

36. Marafioti, T. et al. The inducible T-cell co-stimulator molecule is expressed on subsets of $\mathrm{T}$ cells and is a new marker of lymphomas of $\mathrm{T}$ follicular helper cellderivation. Haematologica 95, 432-439 (2010).

37. Satoh, M. et al. Widespread susceptibility among inbred mouse strains to the induction of lupus autoantibodies by pristane. Clin. Exp. Immunol. 121, 399-405 (2000).

38. Webb, R. et al. A polymorphism within IL21R confers risk for systemic lupus erythematosus. Arthritis Rheum. 60, 2402-2407 (2009).

39. Lan, Y., Luo, B., Wang, J. L., Jiang, Y. W. \& Wei, Y. S. The association of interleukin-21 polymorphisms with interleukin-21 serum levels and risk of systemic lupus erythematosus. Gene. 538, 94-98 (2014).

40. Herber, D. et al. IL-21 has a pathogenic role in a lupus-prone mouse model and its blockade with IL-21R.Fc reduces disease progression. J. Immunol. 178, 3822-3830 (2007).

41. Choi, J. Y. et al. Disruption of pathogenic cellular networks by IL-21 blockade leads to disease amelioration in murine lupus. J. Immunol. 198, 2578-2588 (2017).

42. Bubier, J. A. et al. A critical role for IL-21 receptor signaling in the pathogenesis of systemic lupus erythematosus in BXSB-Yaa mice. Proc. Natl Acad. Sci. USA 106, 1518-1523 (2009).

43. Nakagawa, Y. et al. Impaired expression of ActlmRNA in B cells of patients with Sjogren's syndrome. Jpn. J. Clin. Immunol. 35, 75-80 (2012).

44. Boisson, B. et al. An ACT1 mutation selectively abolishes interleukin-17 responses in humans with chronic mucocutaneous candidiasis. Immunity 39, 676-686 (2013).

\section{Acknowledgments}

This work was supported by the US National Institutes of Health (grants 5R01NS07199605 and 1RO1AA023722 to X.L.), National Science Foundation of China (81701235 to
C.Z.), P40 OD010995 and P30 DK034987 to National Gnotobiotic Rodent Resource Center. W.J.L. is supported by the Division of Intramural Research, NHLBI, NIH. We thank AML Laboratories and the LRI Histology Core for processing tissue samples for histology; Jin Ma, Wen Qian, Jeong-Su Do, and Booki Min at the LRI for technical support; Dr. Yuxin Wang and Dr. George R. Stark at the LRI for providing STAT3 plasmid and critical discussions; Dr. Jürgen Scheller and Dr. Christoph Garbers in Germany for providing IL-23R and IL-6R plasmids.

\section{Author contributions}

X.L. conceived and coordinated the study. C.Z. and X.L. wrote the manuscript. C.Z., C.W., and M.J. conducted majority of experiments and analyzed the data. C.G., F.L., J.X. F.T., and R.B.S. helped with experiment. E.Y., F.L., X.C., B.N.M., Y.X., and H.W. provided technical support. J.G., J.C., and A.D. performed the mass spec and analyzed the data. R.B.S., H.S., M.E.H., F.S., S.C.M., K.C., W.J.L., and T.N.J. provided critical discussion and helped to revise the manuscript.

\section{Additional information}

Supplementary Information accompanies this paper at https://doi.org/10.1038/s41467018-04974-3.

Competing interests: W.J.L. is an inventor on NIH patents related to IL-21. The remaining authors declare no competing interests.

Reprints and permission information is available online at http://npg.nature.com/ reprintsandpermissions/

Publisher's note: Springer Nature remains neutral with regard to jurisdictional claims in published maps and institutional affiliations.

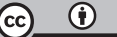

Open Access This article is licensed under a Creative Commons Attribution 4.0 International License, which permits use, sharing, adaptation, distribution and reproduction in any medium or format, as long as you give appropriate credit to the original author(s) and the source, provide a link to the Creative Commons license, and indicate if changes were made. The images or other third party material in this article are included in the article's Creative Commons license, unless indicated otherwise in a credit line to the material. If material is not included in the article's Creative Commons license and your intended use is not permitted by statutory regulation or exceeds the permitted use, you will need to obtain permission directly from the copyright holder. To view a copy of this license, visit http://creativecommons.org/ licenses/by/4.0/.

(c) The Author(s) 2018 